\title{
Fabrication and heat treatment of ceramic- reinforced aluminium matrix composites - a review
}

\author{
Dipti Kanta Das ${ }^{\dagger}$, Purna Chandra Mishra ${ }^{*}$, Saranjit Singh ${ }^{\dagger}$ and Swati Pattanaik ${ }^{\dagger}$
}

\begin{abstract}
Ceramic-reinforced aluminium matrix composites have attracted considerable attention in engineering applications as a result of their relatively low costs and characteristic isotropic properties. Reinforcement materials include carbides, nitrides and oxides. In an effort to achieve optimality in structure and properties of ceramic-reinforced metal matrix composites (MMCs), various fabrication and heat treatment techniques have evolved over the last 20 years. In this paper, the status of the research and development in fabrication and heat treatment techniques of ceramic-reinforced aluminium matrix composites is reviewed, with a major focus on material systems in terms of chemical compositions, weight or volume fraction, particle size of reinforcement, fabrication methods and heat treatment procedures. Various optical measurement techniques used by the researchers are highlighted. Also, limitations and needs of the technique in composite fabrication are presented in the literature. The full potential of various methods for fabricating ceramic-reinforced aluminium matrix composites is yet to be explored.
\end{abstract}

Keywords: Permanent mould technique; Stir casting; ASM T6; Aluminium matrix composites; Heat treatment

\section{Review}

Introduction

Metal matrix composites are combinations of two or more chemically non-reactive materials to form a new material system with enhanced material properties, in which titanium, aluminium and magnesium are popularly used as matrix metals and some non-metallic materials, commonly ceramics such as silicon carbide, aluminium oxide, graphite or fly ash may be used as reinforcing materials (Pandey 2004; Surappa 2003). Silicon carbide-reinforced aluminium matrix composites are advanced engineering materials with improved physical and mechanical properties as compared to their corresponding monolithic alloys. Reinforcement of particles or short fibres of $\mathrm{SiC}$ has proved to be advantageous since it offers the composite materials having virtually isotropic properties at low cost. In recent years, metal matrix composites find their extensive engineering application due to their high strength-to-weight ratio, stiffness and resistance to corrosion and high temperature, especially

\footnotetext{
* Correspondence: pcmmech@yahoo.co.in

${ }^{\dagger}$ Equal contributors

School of Mechanical Engineering, KIIT University, Bhubaneswar, Odisha 751024, India
}

under creep conditions, for which they can be successfully used in aircraft and automobile engine technologies (Divecha et al. 1981; Weinert 1993; Khalifa and Mahmoud 2009; Reddy and Zitoun 2010b). Experimental works on SiC-based technology has gained more importance in aerospace, nuclear, automobile, chemical and cryogenic applications (Adalarasan et al. 2011). One of the major challenges during fabrication of composite material is uniform distribution of reinforcing agent in the matrix phase, which directly affects on the properties and quality of the composite material (Singla et al. 2009). Mechanical properties of a material can be tailored by subjecting it into proper heat treatment condition.

\section{Fabrication of aluminium MMC}

Hung et al. (1995) fabricated 22 wt.\% SiCp-reinforced A 359 metal matrix composite (MMC) by permanent mould casting technique with an average stirring speed of $250 \mathrm{rpm}$ and at pouring temperatures of $700^{\circ} \mathrm{C}$ to $710^{\circ} \mathrm{C}$. They also fabricated 20 wt.\% SiCp-reinforced L2 matrix composites by powder forming applying cold isostatic pressure of 3,700 bar for $5 \mathrm{~min}$. Song et al. (1995) fabricated 20 volume fraction of SiCp (of size 3 and $20 \mu \mathrm{m}$ ) reinforced Al 2014

\section{黑 Springer}


and $\mathrm{Al} 6061$ matrix composites, and the uniformity of distribution of $\mathrm{SiC}$ particles in matrix material was confirmed by optical micrographs. Figure 1 shows the distribution of 20 - and 3- $\mu \mathrm{m} \mathrm{SiC}$ particles in the 6061 Al-based composites in the optical micrographs. Srivatsan and Prakash (1995) fabricated 0.2 and 0.5 volume fractions SiCp (of nominal size $16 \mu \mathrm{m}$ ) reinforced $\mathrm{Al} 2080$ matrix composites at Aluminium Company of America (ALCOA), using proprietary dry blending techniques, in which the blend was cold isostatically compacted, degassed and vacuum hot pressed to produce a fully dense billet. They suggested that blending facilitates homogeneous distribution of the $\mathrm{SiC}$ in the matrix material. Hung et al. (1996) used 10 and 20 vol.\% SiC-reinforced A 359 MMCs supplied by Duralcan (San Diego, CA, USA), fabricated by

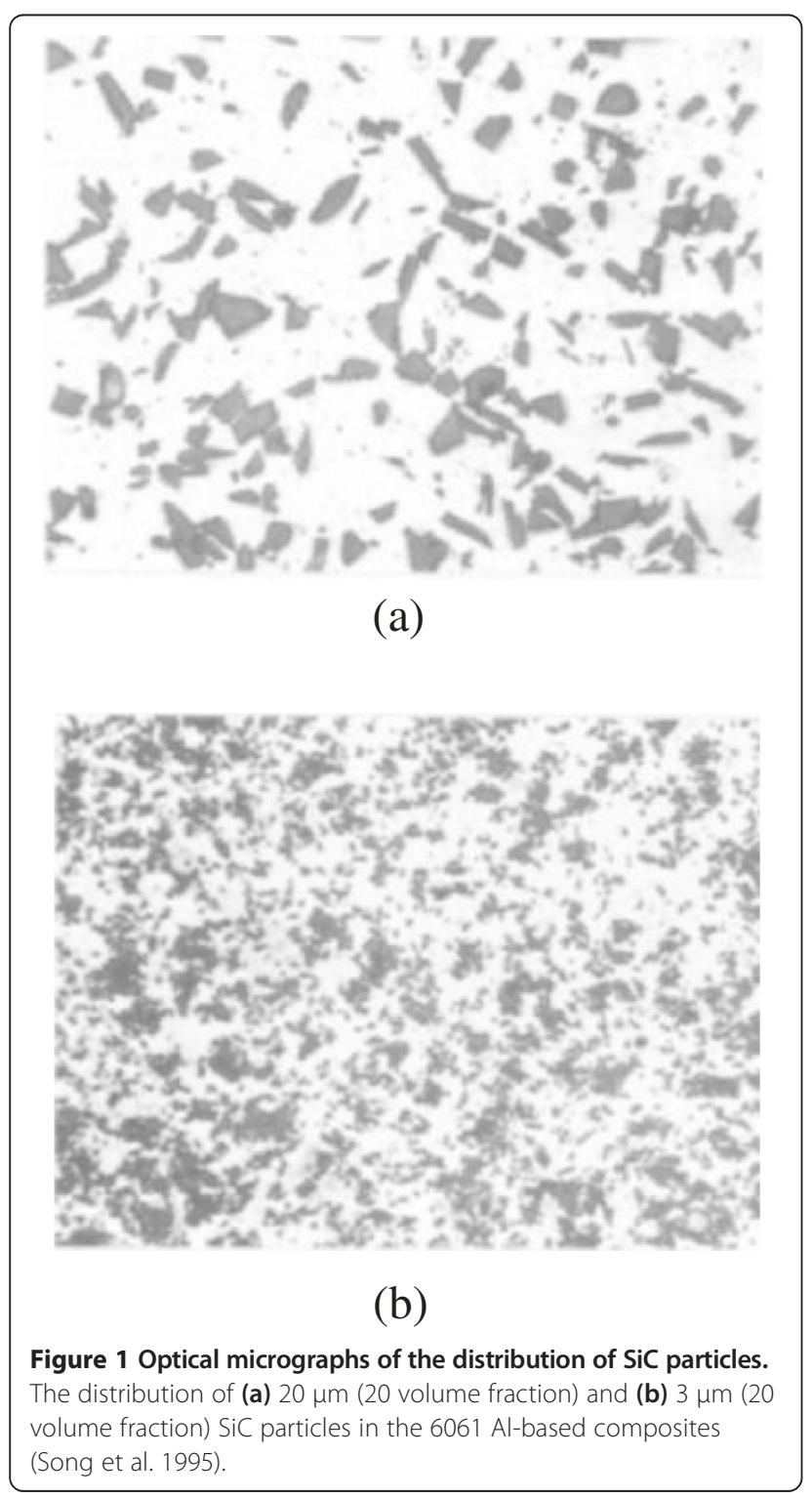

permanent mould casting at pouring temperatures of $700^{\circ} \mathrm{C}$ to $710^{\circ} \mathrm{C}$ and at an average stirring rate of $250 \mathrm{rpm}$. Sahin and Murphy (1996) used metal infiltration technique to produce $\mathrm{SiC}$-coated unidirectional boron fibre-reinforced Al 2014 matrix composites, where the fibre reinforcement was in the form of wide taps made of continuous fibres placed together with titanium tape. Layers of tape were cut and stacked together in the mould to give 16 and 32 volume fractions of reinforcement. The fibre tapes were parallel to each other and continuous across the entire length of the composite plates. Xu et al. (1997) prepared two commercial composites of $\mathrm{Al} 359 / \mathrm{SiC}$ (10 and 20 volume fractions) by conventional stir casting treated by hot isostatic pressing (HIP) under different pressures and temperatures. Ko and Yoo (1998) fabricated hybrid metal matrix composites with $\mathrm{SiC}_{\text {whisker }} / \mathrm{SiC}_{\text {particulate }}$ ratios of 1:1, 1:2 and 1:3 and single-reinforcement composites reinforced with $\mathrm{SiC}_{\text {whisker }}$ or $\mathrm{SiC}_{\text {particulate }}$, by powder metallurgy process to compare hot deformation behaviour of the hybrid composites with that of the singlereinforcement composites. Fang et al. (1997) fabricated 16 vol.\% alumina fibre-reinforced $\mathrm{K} 10 \mathrm{Mg} 85 \mathrm{Al}$ alloy $(\mathrm{Al}+10 \% \mathrm{Mg})$ matrix composite by gas pressurized liquid metal infiltration technique, which involves preheating of $16 \%$ Saffil alumina chopped fibre to $450^{\circ} \mathrm{C}$ and superheating of the matrix alloy melt to $850^{\circ} \mathrm{C}$. A gas pressure of $3 \mathrm{MPa}$ was introduced into the die cavity after pouring the melt to conduct unidirectional infiltration. They also fabricated in situ titanium diboridereinforced Al-based composite, melting Al-4 wt.\% Cu alloy to $850^{\circ} \mathrm{C}$ and then adding two types of compounds, $\mathrm{K}_{2} \mathrm{TiF}_{6}$ and $\mathrm{KBF}_{4}$, in an atomic ratio of Ti:2B by stirring. $\mathrm{Lu}$ et al. (1999) employed powder metallurgy process to produce $\mathrm{Al}-5 \% \mathrm{Cu} / \mathrm{SiC} \mathrm{MMC}$ containing $\mathrm{Al}-\mathrm{Cu}$ powder of 280 grits and $\mathrm{SiC}$ particles with an average particle size of $3.5 \mu \mathrm{m}$ at a volume fraction of $15 \%$, which were compacted by hot compression under vacuum. The defect-free and uniform distribution of $\mathrm{SiC}$ particles in the composite was confirmed by optical micrograph studies, which is shown in Figure 2. Manoharan and Gupta (1999) fabricated SiCp (of average size $35 \mu \mathrm{m}$ ) reinforced AA 1050 composite by disintegrated melt deposition (DMD) technique, where the properly cleaned $\mathrm{Al}$ alloy was heated to a temperature of $950^{\circ} \mathrm{C}$ and $\mathrm{SiCp}$, preheated up to $950^{\circ} \mathrm{C}$ for $90 \mathrm{~min}$, was added to it. The slurry was then mixed thoroughly for $10 \mathrm{~min}$ by an impeller arrangement to achieve uniform distribution of $\mathrm{SiCp}$ in the $\mathrm{Al}$ matrix. After thorough mixing, the hot composite slurry was poured into the metallic mould, during which the melt was disintegrated by two jets of argon gas oriented normal to the melt stream. Jayaram and Biswas (1999) casted $\mathrm{Al}$ alloy containing $\mathrm{Si}, \mathrm{Zn}$ and $\mathrm{Mg}$ as alloying elements and fabricated SiC-reinforced 


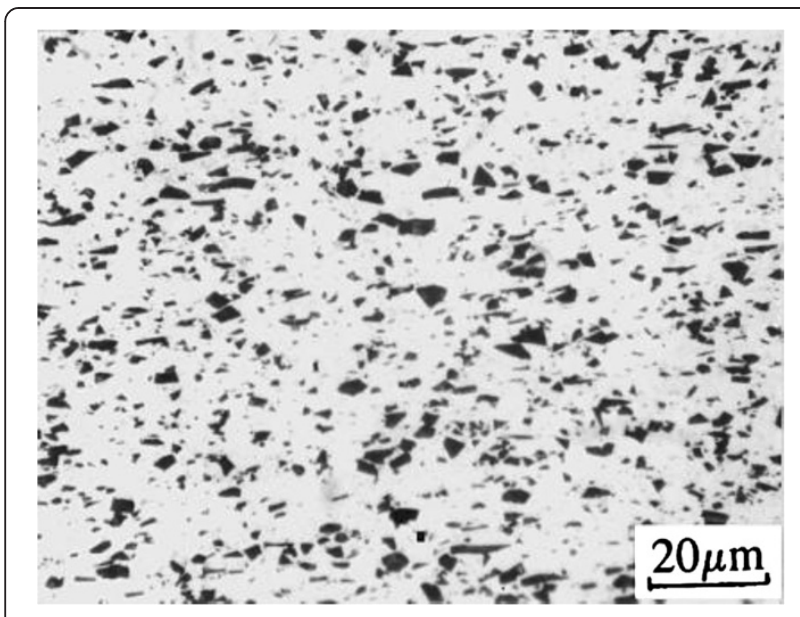

Figure 2 An optical micrograph of the as-prepared Al-5\% Cu/ SiC (3.5 $\mu \mathrm{m}, 15$ volume fraction) composite (Lu et al. 1999).

$\mathrm{Al}$ matrix composites by melt oxidation route. The alloy was casted into flat plates and homogenized at $450^{\circ} \mathrm{C}$ to $500^{\circ} \mathrm{C}$ and the $\mathrm{SiC}$ preforms (mean size ranging from 5 to $300 \mu \mathrm{m}$ ), prepared by cold pressing, followed by a heat treatment at $1,200^{\circ} \mathrm{C}$ to $1,400^{\circ} \mathrm{C}$. The alloy plate and preform are placed in contact and heated in a crucible to temperatures of $1,000^{\circ} \mathrm{C}$ to $1,200^{\circ} \mathrm{C}$ and allowed to remain at that temperature for periods of 3 to 5 days. Following cooling, the preform was removed, sectioned into specimens for mechanical tests and optical metallography. Dual process of mechanical alloying and powder metallurgy was adopted by Kwok and Lim (1999) to manufacture $\mathrm{Al}-4.5 \% \mathrm{Cu} / 13$ vol.\% $\mathrm{SiCp}$ composites, where high-purity aluminium $(150 \mu \mathrm{m})$, copper $(150 \mu \mathrm{m})$ and silicon carbide $(50 \mu \mathrm{m})$ were mechanically alloyed in a ball mill under steady-state condition for $10 \mathrm{~h}$ at two different speeds of 86 and $163 \mathrm{rpm}$ and the generated powders were subjected to compaction at a pressure of $420 \mathrm{MPa}$, sintered at $590^{\circ} \mathrm{C}$ for $5 \mathrm{~h}$.

It can be clearly observed that there is slight agglomeration of $\mathrm{SiC}$ particulates at some places in Figure 1a, and distribution of $\mathrm{SiC}$ particulates is more uniform in Figure $1 \mathrm{~b}$. The comparison reveals that the size of reinforcement particulates is one of the influencing factors for their uniform distribution in MMC, and the distribution becomes more uniform as the particle size reduces. It can be observed that there is non-uniformity of size of $\mathrm{SiC}$ particulates in Figure 2. The uniformity of distribution of $\mathrm{SiC}$ particulates is better as compared to that of Figure 1a and slightly poor as compared to that of Figure 1b. This difference might be either due to variation of particulate size or due to variation of volume fraction of reinforcement or even might be due to variation of composition of matrix material, which is difficult to predict, since all the three parameters of the composite represented in Figure 2, i.e. matrix material
(Al-5\% Cu), size (average $3.5 \mu \mathrm{m})$ and volume fraction (15\%) of reinforcement, are different as compared to those of Figure 1.

Chen et al. (2000) fabricated SiCp reinforced with A 356 alloy matrix by molten liquid aluminium stirring method, whereas Davidson and Regener (2000) manufactured 10 wt.\% of SiCp-reinforced AA 6061 matrix composite by double-sided cold compaction process applying a pressure of $385 \mathrm{MPa}$ for 5 min followed by pressureless sintering at $610^{\circ} \mathrm{C}$ for $5 \mathrm{~h}$. Kumar and Dwarakadasa (2000) prepared 9\% and 18\% SiCp (of average particle size $40 \mu \mathrm{m}$ ) reinforced $\mathrm{Al}-\mathrm{Zn}-\mathrm{Mg}$ alloy (equivalent to $\mathrm{Al}$ 7075) matrix composites by liquid metal processing or stir casting technique. Figure 3 shows the size, shape and morphology of SiCp used.

Hamed et al. (2001) fabricated 10 wt.\% SiCp-reinforced $\mathrm{Al} 359$ composite by ingot metallurgy technique, where the $\mathrm{Al}$ alloy was melted at a temperature of $735^{\circ} \mathrm{C} \pm 5^{\circ} \mathrm{C}$ and then preheated $\mathrm{SiC}$ particulates were added into the melt at a feed rate of $0.5 \mathrm{~g} / \mathrm{min}$ and the mixture was stirred ultrasonically. The composite slurry was then poured into a preheated permanent steel mould. Cocen and Onel (2002) used melt stirring technique to prepare $\mathrm{Al}-5 \% \mathrm{Si}-0.2 \% \mathrm{Mg}$ alloy and $\mathrm{SiC}$-reinforced $\mathrm{Al}-5 \% \mathrm{Si}-0.2 \% \mathrm{Mg}$ composite in an induction furnace under an argon gas protective atmosphere, whereas Borrego et al. (2002) fabricated SiCreinforced $\mathrm{Al} 6061$ matrix composite by powder metallurgy route which involves dry blending of aluminium powder with $15 \mathrm{vol} \%$ of the $\mathrm{SiC}$ whiskers, followed by homogenization of the blends at $150 \mathrm{rpm}$ for $1 \mathrm{~h}$ and compaction at $100^{\circ} \mathrm{C}$ with increasing pressure up to $300 \mathrm{MPa}$ in a die. Naher et al. (2004) designed and built a new quick quench stir caster, fitted with thermocouple and temperature controller arrangement to fabricate $\mathrm{MMC}$ ingot. Data logger facilities were incorporated to record

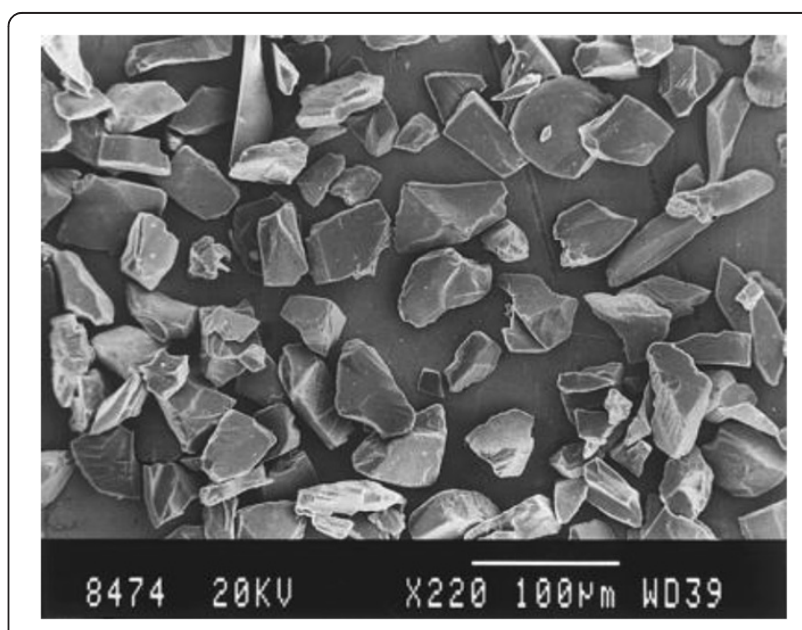

Figure 3 Size, shape and morphology of SiCp (Kumar and Dwarakadasa 2000). 
the temperature at a rate of $1 \mathrm{~Hz}$. While fabricating $\mathrm{SiCp}$ reinforced $\mathrm{Al} 356$ composites using the quick quench compocasting method, he reported that full incorporation of $\mathrm{SiC}$ particles into the aluminium matrix can be obtained by stirring the MMC slurry in the semi-solid state without any addition of wetting agent. Zhiqiang et al. (2005) prepared $\mathrm{SiC}$-reinforced Al-Si-Cu-Mg matrix composite by powder metallurgy technology, which involves compaction of powder in a cold compaction mould in a material testing machine, followed by sintering the billet in the tube furnace with electric resistance heating. Natarajan et al. (2006) fabricated SiC-reinforced A 356 composite by liquid metallurgy route, in which the alloy was melted in an electric furnace and stirred by a motorized stirrer, as a result of which a vortex was created on the top surface. Preheated $\mathrm{SiC}$ was added to the melt with continuous stirring, and finally, the composite slurry was poured into the cast iron mould. Fu-min et al. (2007) manufactured SiC-reinforced $\mathrm{Al}-\mathrm{Mg}$-Si matrix composite by pressureless infiltration technique in the presence of nitrogen at $850^{\circ} \mathrm{C}$. Ronald et al. (2007) manufactured SiCp (50- $\mu$ m size/30 volume fraction) reinforced $\mathrm{Al} 2124$ alloy matrix composite through the powder metallurgy route. Figure 4 shows uniform distribution of $\mathrm{SiC}$ particulate in the $\mathrm{Al} 2024$ matrix in SEM image.

Kalkanli and Yilmaz (2008) fabricated SiC-reinforced Al 7075 composite by the process of vertical pressure casting. In the process, first, the alloy was prepared by adding its various elements except magnesium into the induction furnace at temperatures of $750^{\circ} \mathrm{C}$ to $780^{\circ} \mathrm{C}$. After attaining a homogeneous phase, magnesium was added followed by addition of $\mathrm{SiC}$ powder with continuous stirring until a highly viscous phase was obtained. The viscous fluid was then moved to a die by squeeze casting technique by applying a pressure of $80 \mathrm{MPa}$. Balogun et al. (2008) produced 5, 10, 20 and 30 vol.\% of $\mathrm{SiC}$ (of grain sizes 240, 420, 840 and 4,200 $\mu \mathrm{m}$ )

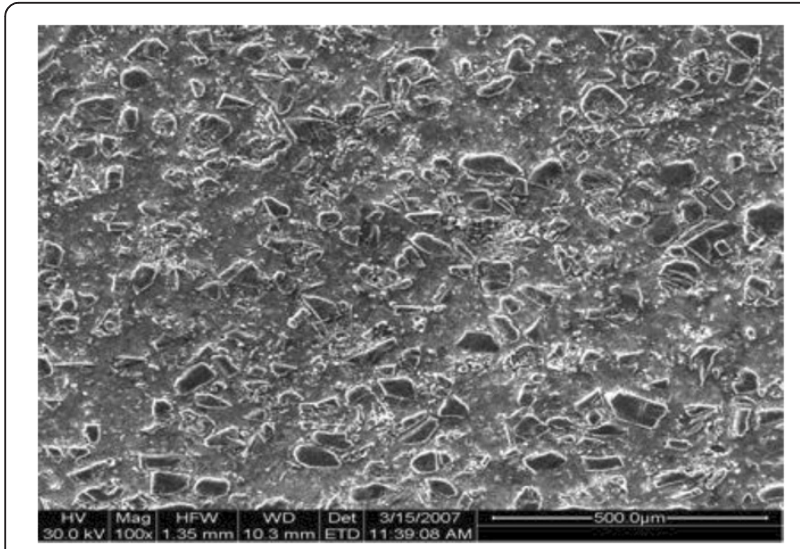

Figure 4 SEM micrograph of the SiC $(50 \mu \mathrm{m}, 30$ volume fraction)/Al 2124 composite material (Ronald et al. 2007). reinforced AA 6063 MMC by liquid metallurgy route in an oil fired cupola furnace with two varying charging modes using the compocasting method. Properly cleaned aluminium alloy ingots were superheated to $700^{\circ} \mathrm{C}$, and $\mathrm{SiC}$ particulates were added to the molten metal and continuously stirred before sand casting. Kok (2008) fabricated 30 wt.\% $\mathrm{Al}_{2} \mathrm{O}_{3}$ particle-reinforced $\mathrm{Al}$ 2024 alloy composites by vortex method with subsequently applied pressure of $6 \mathrm{MPa}$, using a resistance-heated furnace under argon gas. The chemical composition of the 2024 Al alloy matrix is shown in Table 1.

Mindivan et al. (2008) manufactured disc-shaped composites with 2618, 6082, 7012 and 7075 aluminium alloys as matrix and $\mathrm{SiC}$ as reinforcement. The process involved heating the aluminium alloy up to $800^{\circ} \mathrm{C}$ and $\mathrm{SiC}$ particles up to $1,000^{\circ} \mathrm{C}$ before mixing to the molten alloy. The molten $\mathrm{SiC}$ and alloy slurry was poured into the mould, which was preheated up to a temperature of $300^{\circ} \mathrm{C}$. The mixture was hydraulically pressurized up to $600 \mathrm{MPa}$. The uniformity of distribution of $\mathrm{SiC}$ in the alloy was confirmed by macroscopic and microscopic examination of the composites.

Rao et al. (2009) synthesized Al-Zn-Mg-SiCp composite by solidification processing (stir casting) route which involved melting the alloy, addition of preheated $\mathrm{SiC}$ particles and thorough mixing. Then, the slurry was poured into the mould and allowed to cool. Hassan et al. (2009) fabricated $\mathrm{SiC}$-reinforced $\mathrm{Al}-\mathrm{Mg}-\mathrm{Cu}$ composite by stir casting process, in which the aluminium ingots and copper powder were melted together at $850^{\circ} \mathrm{C}$ and pre-oxidized $\mathrm{SiC}$ powder was added to the melt. Then, $\mathrm{Mg}$ was added to the melt to enhance the wettability between the metal matrix and reinforcement particles. The mixture was poured into a semi-permanent steel mould and was left for air cooling. Singla et al. (2009) developed a conventional low-cost method for producing MMCs and to obtain homogenous dispersion of ceramic material. Aluminium (98.41\% C.P.)/SiC (320-grit) MMC was fabricated with varying weight fractions of $\mathrm{SiC}(5 \%$, $10 \%, 15 \%, 20 \%, 25 \%$ and $30 \%$ ) using a two-step mixing method of stir casting technique. Scraps of aluminium were preheated at $450^{\circ} \mathrm{C}$ for 3 to $4 \mathrm{~h}$, and $\mathrm{SiC}$ particles were preheated at $1,100^{\circ} \mathrm{C}$ for 1 to $3 \mathrm{~h}$ to make their surfaces oxidized. Figure 5 shows the schematic view of the furnace. The furnace temperature was then raised above the liquidus to melt the alloy scraps completely and was then cooled down just below the liquidus to keep the slurry in a semi-solid state. At this stage, the preheated $\mathrm{SiC}$ particles were added and mixed manually. After sufficient

Table 1 The chemical composition (wt.\%) of Al 2024 matrix alloy

\begin{tabular}{cccccc}
\hline $\mathbf{C u}$ & Mg & Si & Mn & Zn & Al \\
\hline 3.23 & 0.81 & 0.74 & 0.54 & 0.13 & Rest \\
\hline
\end{tabular}




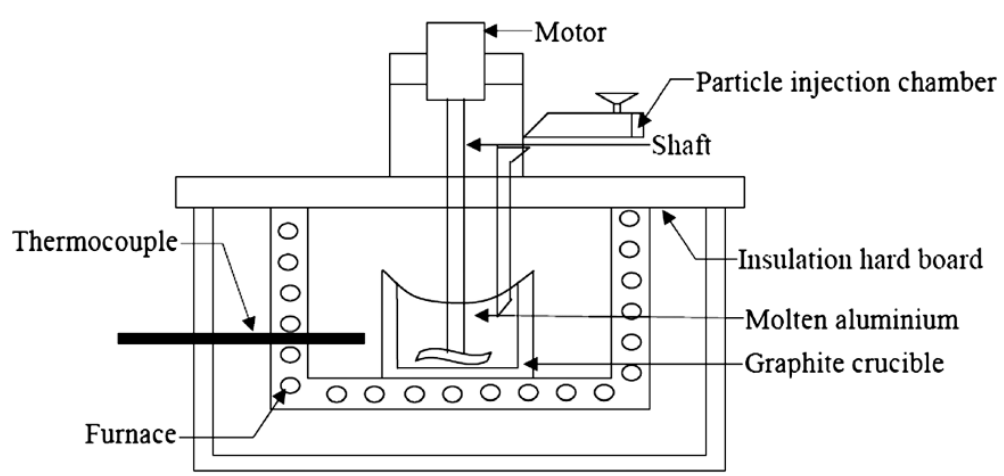

Figure 5 Schematic view of setup for fabrication of composite (Singla et al. 2009).

manual mixing, the composite slurry was reheated to fully liquid state (up to $760^{\circ} \mathrm{C} \pm 10^{\circ} \mathrm{C}$ ), and then automatic mechanical mixing was carried out for about $10 \mathrm{~min}$ at a normal stirring rate of $600 \mathrm{rpm}$. The position of stirrer was such that $35 \%$ of material was below the stirrer and $65 \%$ of material was above the stirrer. Crucible used for pouring of composite slurry in the sand mould was also heated up to $760^{\circ} \mathrm{C}$.

Adeosun et al. (2009) fabricated 0 to 50 vol.\% SiCp (1 and $60 \mu \mathrm{m}$ ) reinforced $\mathrm{Al} 1200$ alloy composite in a crucible furnace; some of which were homogenized at $430^{\circ} \mathrm{C}$ for $8 \mathrm{~h}$ and air-cooled.

Khalifa and Mahmoud (2009) prepared 5, 10, and $15 \mathrm{wt}$. $\%$ of SiCp (of average size of $60 \mu \mathrm{m}$ ) reinforced $\mathrm{Al} 6063$ by vortex method, which involves melting the matrix at $710^{\circ} \mathrm{C}$ and degassing it with dry nitrogen gas to minimize the oxidation of the molten metal. The melt was then stirred with a steel stirrer at a speed of $750 \mathrm{rpm}$ for 10 to $15 \mathrm{~min}$, and $\mathrm{SiC}$ particles, preheated to a temperature of $300^{\circ} \mathrm{C}$ for $2 \mathrm{~h}$, were added to the vortex of molten metal during stirring. The composite slurry was poured into a metallic mould, after the stirring was completed. Bains and Manna (2010) prepared 5 and 10 vol.\% SiCp (of size $100 \mu \mathrm{m}$ ) reinforced $\mathrm{Al} 6063$ alloy, where the matrix alloy was preheated at $300^{\circ}$ $\mathrm{C}$ for 1 to $2 \mathrm{~h}$ before melting and the $\mathrm{SiCp}$ was preheated at $300^{\circ} \mathrm{C}$ for $1 \mathrm{~h}$ before mixing to make the surface of $\mathrm{SiCp}$ oxidized. The furnace temperature was raised above the liquidus temperature to melt the alloy completely at $750^{\circ} \mathrm{C}$ and was then cooled down just below the liquidus temperature to keep the slurry in a semi-solid state. Then, the preheated SiCp were added to a semi-solid metal and mixed manually for 1 to $1.5 \mathrm{~min}$. The composite slurry was then reheated to a fully liquid state, automatic mechanical mixing was done for $30 \mathrm{~min}$ at a stirring rate of $220 \mathrm{rpm}$ and casting was done in a steel mould. Yingfei et al. (2010) produced 15 vol.\% SiCp (of mean size $2 \mu \mathrm{m}$ )/2009 Al composites through powder metallurgy technology.

Suresha and Sridhara (2010) fabricated LM 25-graphite MMC and LM 25-SiC-graphite hybrid MMC with combined weight fraction reinforcement of $2.5 \%, 5 \%, 7.5 \%$ and
$10 \%$ using stir casting technique, whereas Rao et al. (2010) synthesized SiC (20 to $40 \mu \mathrm{m}$ ) reinforced AA 7009 (Al-Zn$\mathrm{Mg}$ ) matrix composite through solidification processing (stir casting) route which involved melting the alloy, adding preheated $\mathrm{SiC}$ particles in the melt by mechanical stirring and finally casting the composite melt in the preheated permanent cast iron mould. Joardar et al. (2011) prepared SiCp (of average particle size $37 \mu \mathrm{m}$ )/LM 6 matrix composites by the stir casting route, where the aluminium alloy was melted in an electric resistance furnace having a clay graphite crucible at a temperature of $750^{\circ} \mathrm{C}$. The melt was then mechanically stirred with a speed of $500 \mathrm{rpm}$ by an impeller, after addition of preheated $\left(900^{\circ} \mathrm{C}\right)$ silicon carbide particles. The pouring temperature of molten composite slurry into a sand mould was $745^{\circ} \mathrm{C}$. The composition of LM 6 is tabulated in Table 2.

Alaneme (2011) developed 6, 12 and 15 vol.\% of SiCp (size $30 \mu \mathrm{m}$ ) reinforced Al 6063 alloy matrix composites using a two-step stir casting method which involved melting the $\mathrm{Al}$ ingots and then cooling to a semi-solid state before introducing the $\mathrm{SiC}$ particulates and dehydrated borax mixture (in the ratio 2:1) and then stirred manually for 10 to $15 \mathrm{~min}$. This was followed by heating of the mixture to $30^{\circ} \mathrm{C}$ above the liquidus and then performing a second stirring using a mechanical stirrer at a revolution of $300 \mathrm{rpm}$ for $10 \mathrm{~min}$ before casting. Table 3 shows the chemical composition result of Al 6063.

Schubert and Nestler (2011) fabricated 25 vol.\% SiC (of particle size ranging 2 to $3 \mu \mathrm{m}$ ) reinforced AA 2124 MMC by powder metallurgy route, where the powder is compacted by hot isostatic pressing, after a high-energy mixing process.

Kumar et al. (2012) produced $\mathrm{SiC}$ (of size 30 to $50 \mu \mathrm{m}$ and weight percentage of 5,10 and 15) reinforced $\mathrm{Al}$ 6061 matrix composite by liquid metallurgy technique,

Table 2 Chemical composition (wt.\%) of LM 6

\begin{tabular}{ccccccccccc}
\hline Si & $\mathbf{C u}$ & $\mathbf{M g}$ & $\mathbf{F e}$ & $\mathbf{M n}$ & $\mathbf{N i}$ & $\mathbf{Z n}$ & $\mathbf{P b}$ & $\mathbf{S b}$ & $\mathbf{T i}$ & $\mathbf{A l}$ \\
\hline 10 to 13 & 0.1 & 0.1 & 0.6 & 0.5 & 0.1 & 0.1 & 0.1 & 0.05 & 0.2 & Rest \\
\hline
\end{tabular}


Table 3 Chemical composition result (wt.\%) of Al 6063

\begin{tabular}{ccccccccc}
\hline $\mathbf{S i}$ & $\mathbf{F e}$ & $\mathbf{C u}$ & $\mathbf{M n}$ & $\mathbf{M g}$ & $\mathbf{Z n}$ & $\mathbf{C r}$ & $\mathbf{T i}$ & $\mathbf{A l}$ \\
\hline 0.46 & 0.23 & 0.02 & 0.03 & 0.51 & 0.02 & 0.03 & 0.03 & Rest \\
\hline
\end{tabular}

where the $\mathrm{SiC}$ was first cleaned in distilled water and dried at $90^{\circ} \mathrm{C}$. It was then preheated to a temperature of $500^{\circ} \mathrm{C}$ and added into the vortex of molten aluminium, which was created by rotating an alumina-coated stainless steel stirrer at a speed of $550 \mathrm{rpm}$. The composite slurry was then degassed using pure nitrogen for about 3 to $4 \mathrm{~min}$, and then the resulting mixture was tilt-poured into a preheated permanent mould. Alaneme and Aluko (2012) manufactured $\mathrm{SiC}(3,6,9$ and 12 vol.\%)/Al 6063 alloy matrix composites by double stir casting process, where the $\mathrm{Al}$ alloy billets were heated up to a temperature of $750^{\circ} \mathrm{C}$ and then allowed to cool to $600^{\circ} \mathrm{C}$, which is slightly below the liquidus temperature, to a semi-solid state. Then, the $\mathrm{SiC}$ and dehydrated borax mixture (in a ratio 2:1) was added into the melt, and manual stirring of the slurry was performed for $20 \mathrm{~min}$. After manual stirring, the composite slurry was reheated and maintained at a temperature of $750^{\circ} \mathrm{C} \pm 10^{\circ} \mathrm{C}$, and then mechanical stirring was performed for $20 \mathrm{~min}$ at an average stirring rate of $300 \mathrm{rpm}$. Casting was then performed in sand moulds at a pouring temperature of $720^{\circ} \mathrm{C}$. Vanarotti et al. (2012) manufactured $\mathrm{A} 356 / \mathrm{SiC}$ composite by stir casting technique in a resistance furnace, where the matrix alloy was preheated at $450^{\circ} \mathrm{C}$ for 3 to $4 \mathrm{~h}$ and $\mathrm{SiC}$ particles were preheated at $1,100^{\circ} \mathrm{C}$ for 1 to $3 \mathrm{~h}$ to make their surfaces oxidized. Furnace temperature was first raised above the liquidus to melt the alloy completely and was then cooled down just below the liquidus temperature to keep the slurry in a semi-solid state. Then, the preheated $\mathrm{SiC}$ particles were added and mixed manually. Then, the composite slurry was reheated to a fully liquid state, i.e. up to a temperature of $730^{\circ} \mathrm{C} \pm 10^{\circ} \mathrm{C}$, and then automatic mechanical mixing was carried out for about $20 \mathrm{~min}$ at an average stirring rate of $300 \mathrm{rpm}$. The pouring temperature of the slurry to a preheated $\left(350^{\circ} \mathrm{C}\right)$ permanent graphite mould was maintained at around $720^{\circ} \mathrm{C}$. Ravesh and Garg (2012) synthesized SiC- and fly ash-reinforced Al6061 alloy composite by stir casting technique, in which the alloy was melted at $820^{\circ} \mathrm{C}$ in a resistance furnace. The fly ash was preheated at $400^{\circ} \mathrm{C}$, and $\mathrm{SiC}$ was preheated at $800^{\circ} \mathrm{C}$ for $1 \mathrm{~h}$ to remove moisture and gases from the surface of the particulates. The speed of the stirrer was gradually raised to $800 \mathrm{rpm}$ and the preheated reinforced particles were added with a spoon at a rate of 10 to $20 \mathrm{~g} / \mathrm{min}$ into the melt with constant stirring. Then, the melt was kept in the crucible for approximate half minute in static condition, and then it was poured in the mould. Kumar et al. (2012) fabricated glass and silicon carbide particle-reinforced aluminium hybrid composite by powder metallurgy method, in which cold pressing was used for compaction of the reinforced glass-SiC aluminium hybrid composites.

Behera et al. (2012) fabricated 5, 7.5, 10 and 12.5 wt.\% of SiCp (of average 400-mesh size) reinforced LM 6 alloy MMC by the liquid metal stir casting technique, where the aluminium alloy was melted to a temperature of $750^{\circ} \mathrm{C}$ in graphite crucible, three-phase electric resistance furnace with stirring system (shown in Figure 6). Then, 3 wt.\% Mg has been added with the liquid metal. The melt was then mechanically stirred for 10 to $15 \mathrm{~min}$ by using an impeller at a speed of 400 to $500 \mathrm{rpm}$. During stirring, the preheated (at about $850^{\circ} \mathrm{C}$ to $900^{\circ} \mathrm{C}$ ) $\mathrm{SiC}$ particles were introduced into the melt through the vortex of the molten metal. The composite melt was poured at a temperature of $720^{\circ} \mathrm{C}$ into the stepped green silica sand mould. After pouring, the melt was allowed to cool and solidify in the mould. Figure 7 shows the benchmark model of the casting. The cylindrical furnace used in their work was of electrical resistance type, having control accuracy of molten aluminium temperature of $\pm 5^{\circ} \mathrm{C}$, maximum working temperature of $1,100^{\circ} \mathrm{C}$, PLC automatic temperature control, maximum stirring speed of $800 \mathrm{rpm}$ and hand wheel-based manually tilting molten aluminium drain-off arrangement.

Babu and Krishnan (2012) fabricated $10 \mathrm{wt} . \% \mathrm{SiC}$ and 5 wt.\% $\mathrm{B}_{4} \mathrm{C}$ (both of particle size ranging from 30 to $50 \mu \mathrm{m})$ reinforced $\mathrm{Al} 356$ metal matrix composite using

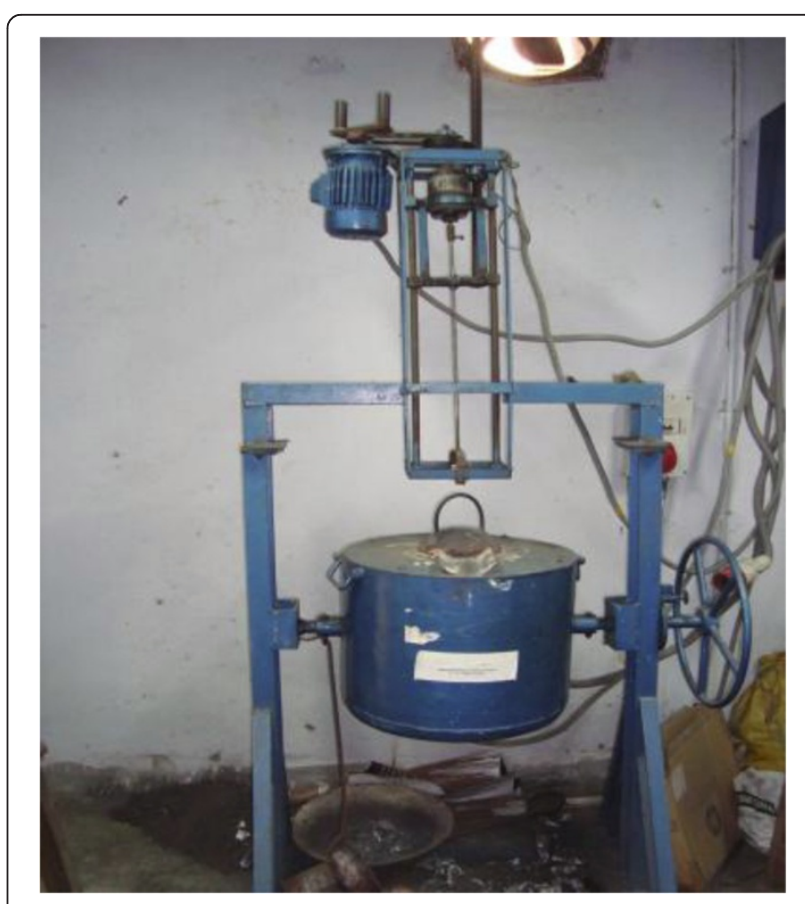

Figure 6 Electric resistance furnace with stirring system (Behera et al. 2012). 


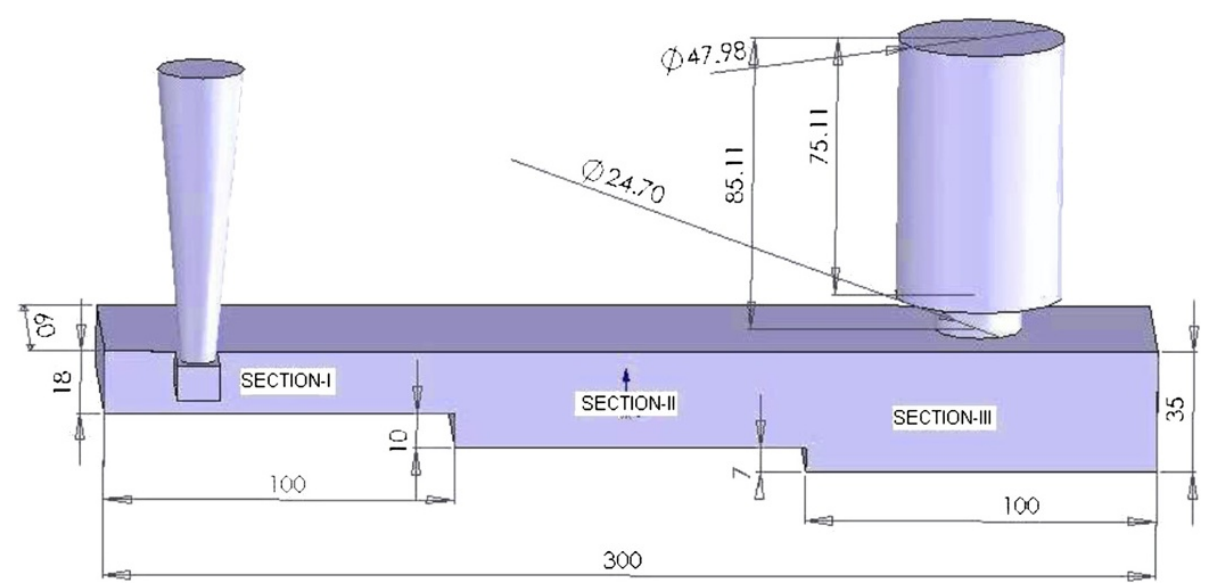

Figure 7 Benchmark model of the stepped casting (dimensions in $\mathrm{mm}$ ) (Behera et al. 2012).

stir casting method. The cleaned matrix alloy was melted in an electric arc furnace up to temperatures of $710^{\circ} \mathrm{C}$ to $725^{\circ} \mathrm{C}$. During melting, all cover flux was added in the furnace and after complete melting of the base alloy; degassing process was carried out by adding hexachloroethane tablets. Mechanical stirring was then conducted for about 5 to $6 \mathrm{~min}$ at $450 \mathrm{rpm}$. $\mathrm{SiC}$ and $\mathrm{B}_{4} \mathrm{C}$ particles, preheated to a temperature of $790^{\circ} \mathrm{C}$ along with magnesium were continuously added to the melt during stirring. The molten mixture was then poured into the steel moulds. Figure 8 shows the microstructure of the $\mathrm{SiC} / \mathrm{B} 4 \mathrm{C} / \mathrm{Al} 356$ hybrid composite specimen. Table 4 shows the chemical composition test result of the hybrid composite specimen.
Kumar and Dhiman (2013) employed stir casting technique to synthesize $7 \mathrm{wt} . \% \mathrm{SiC}$ (of size 27 to $33 \mu \mathrm{m}$ ) and 3 wt.\% graphite (of size 20 to $25 \mu \mathrm{m}$ ) reinforced $\mathrm{Al} 7075$ alloy hybrid metal matrix composites. Table 5 shows the chemical composition of the $\mathrm{Al} 7075$ alloy. The matrix metal was melted above the superheating temperature, i.e. $700^{\circ} \mathrm{C}$ in a graphite crucible under a cover of nitrogen gas by using an electrical resistance heating furnace, and the molten metal was well agitated by a mechanical stirrer to create turbulence motion. The depth of the immersed impeller was approximately two third of the height of the molten metal from the bottom of the crucible and the speed of the stirrer maintained at $600 \mathrm{rpm}$.

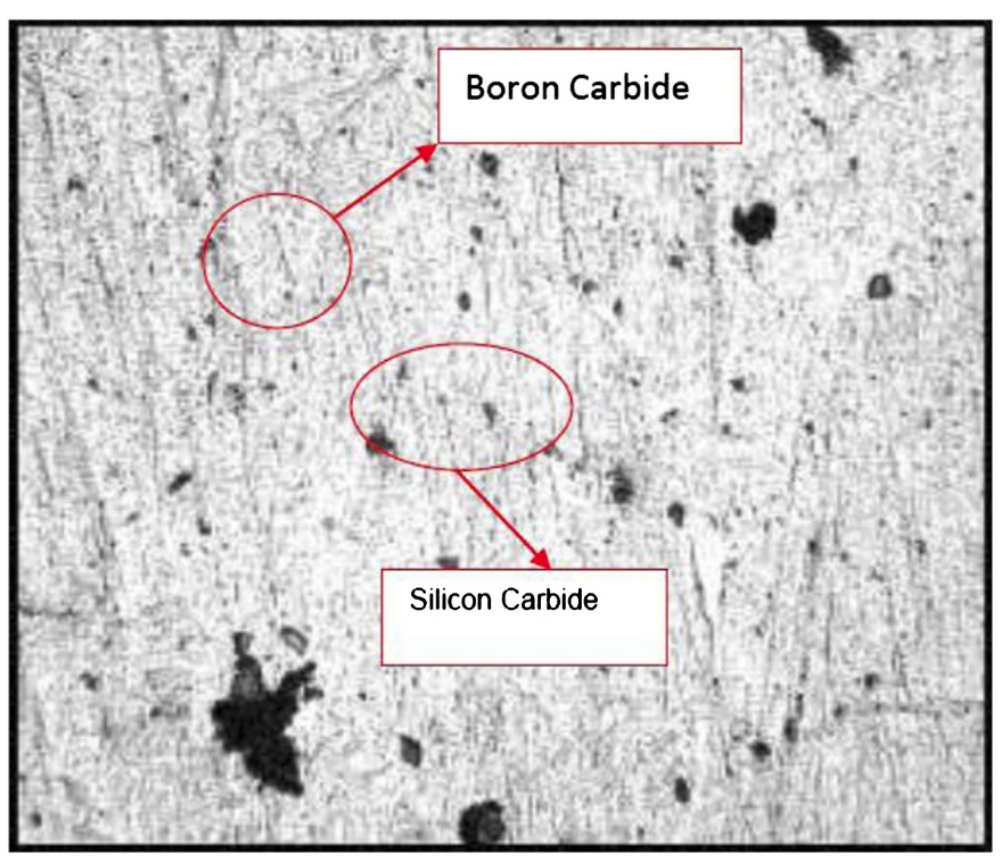

Figure 8 Microstructure of $\mathrm{Al} 356$ reinforced with $10 \% \mathrm{SiC}$ and $5 \% \mathrm{~B} 4 \mathrm{C}$. 
Table 4 Chemical composition of Al 356-SiC (10p) B4C (5P) hybrid MMC

\begin{tabular}{|c|c|c|c|c|c|c|c|c|c|c|c|}
\hline Type of hybrid MMC & Reinforcement & $\% \mathrm{SiC}$ & $\% \mathrm{~B}_{4} \mathrm{C}$ & $\% \mathrm{SiC}$ & $\% \mathrm{Mg}$ & $\% \mathrm{Fe}$ & $\% \mathrm{Cu}$ & $\% \mathrm{Mn}$ & $\% \mathrm{Zn}$ & $\% \mathrm{Ti}$ & $\% \mathrm{Al}$ \\
\hline Particulate MMC & $\mathrm{SiC}$ and $\mathrm{B} 4 \mathrm{C}-30$ to $50 \mu \mathrm{m}$ & 10.00 & 5.00 & 7.88 & 0.65 & 0.25 & 0.17 & 0.08 & 0.08 & 0.19 & Balance \\
\hline
\end{tabular}

During mechanical stirring, 1 wt.\% magnesium was added to increase the wettability of reinforcing particles. Finally, the molten metal was poured into the mild steel die, preheated to a temperature of about $300^{\circ} \mathrm{C}$.

Alaneme et al. (2013) employed a two-step stir casting process for manufacturing bamboo leaf ash (BLA) and $\mathrm{SiC}$-reinforced $\mathrm{Al}-\mathrm{Mg}$-Si alloy hybrid matrix composites with 10 wt.\% reinforcements consisting of 0:10, 2:8, 3:7 and 4:6 BLA and $\mathrm{SiC}$ weight percentages, respectively. The bamboo leaf ash and silicon carbide particles were initially preheated separately at a temperature of $250^{\circ} \mathrm{C}$. The $\mathrm{Al}$ alloy billets were heated to a temperature of $750^{\circ} \mathrm{C} \pm 30^{\circ} \mathrm{C}$ to complete the molten state, followed by cooling to a semi-solid state at a temperature of about $600^{\circ} \mathrm{C}$. The preheated bamboo leaf ash and $\mathrm{SiC}$ particles along with 0.1 wt.\% magnesium were then charged into the melt at this temperature, and stirring of the slurry was performed manually for 5 to $10 \mathrm{~min}$. The composite slurry was then superheated to $800^{\circ} \mathrm{C} \pm 50^{\circ} \mathrm{C}$ and a second stirring performed using a mechanical stirrer with a stirring speed of $400 \mathrm{rpm}$ for $10 \mathrm{~min}$ before casting into prepared sand moulds inserted with chills. Figure 9 shows the photomicrograph of $\mathrm{Al}-\mathrm{Mg}-\mathrm{Si} / 2$ wt.\% BLA8 wt.\% SiC hybrid composite, and Figure 10 shows the EDAX profile obtained from the Al-Mg-Si/2 wt.\% BLA8 wt.\% $\mathrm{SiC}$ hybrid composite confirming the presence of $\mathrm{SiC}, \mathrm{Al}_{2} \mathrm{O}_{3}, \mathrm{SiO}_{2}, \mathrm{Fe}_{2} \mathrm{O}_{3}, \mathrm{~K}_{2} \mathrm{O}$ and $\mathrm{CaO}$.

Umanath et al. (2013) manufactured $\mathrm{SiC}$ and $\mathrm{Al}_{2} \mathrm{O}_{3}$ reinforced $\mathrm{Al} 6061$ hybrid metal matrix composite by stir casting method, in which the Al 6061 alloy was melted in a ceramic crucible in an induction electric resistance furnace up to a temperature of $725^{\circ} \mathrm{C}$ and then it was degassed with nitrogen. The melt was then stirred with alumina-coated stainless steel stirrer at $600 \mathrm{rpm}$ for $20 \mathrm{~min}$. The immersion depth of the stirrer was maintained at about two third on the depth of the melt. During stirring, $\mathrm{SiC}$ and $\mathrm{Al}_{2} \mathrm{O}_{3}$, preheated to $600^{\circ} \mathrm{C}$ for $1 \mathrm{~h}$, in equivalent volume fraction was added into the vortex formed due to stirring. After complete addition of the particles to the molten metal, the liquid composite was tilt-poured into the permanent steel mould, preheated at $250^{\circ} \mathrm{C}$ and then allowed to cool in the atmosphere. The layout of stir casting setup for composite fabrication is

Table 5 The chemical composition of Al 7075 matrix alloy (Kumar and Dhiman 2013)

\begin{tabular}{cccccccccc}
\hline Al & Cr & Cu & Fe & Mg & Zn & Si & Mn & Ti & Other \\
\hline 89.79 & 0.08 & 1.35 & 0.3 & 2.21 & 5.67 & 0.4 & 0.08 & 0.06 & 0.06 \\
\hline
\end{tabular}

shown in Figure 11. Figure 12 shows the optical micrographs of (a) Al6061 alloy $+5 \%$ vol. $\left(\mathrm{SiCp}+\mathrm{Al}_{2} \mathrm{O}_{3} \mathrm{p}\right)$ and (b) Al6061 alloy $+15 \%$ vol. $\left(\mathrm{SiCp}+\mathrm{Al}_{2} \mathrm{O}_{3} \mathrm{p}\right)$.

Boopathi et al. (2013) prepared aluminium-SiC, aluminium-fly ash, aluminium-SiC-fly ash and aluminium-fly ash-SiC metal matrix hybrid composite by stir casting technique. The fly ash, $\mathrm{SiC}$ and their mixture were preheated to $300^{\circ} \mathrm{C}$ for $3 \mathrm{~h}$ to remove moisture. Pure aluminium was melted in a resistance furnace, where the melt temperature was raised up to $720^{\circ} \mathrm{C}$ and then the melt was stirred with the help of a mild steel turbine stirrer for 5 to $7 \mathrm{~min}$ at an impeller speed of $200 \mathrm{rpm}$. To increase the wettability, $1.5 \%$ of pure $\mathrm{Mg}$ was added with all composites. The melt temperature was maintained at $700^{\circ} \mathrm{C}$ during addition of $\mathrm{Mg}, \mathrm{SiC}$, fly ash and $\mathrm{SiC}$-fly ash mixture particles. The dispersion of fly ash and other particles were achieved by the vortex method. The melt with reinforced particulates were poured into the preheated permanent metallic mould, and the pouring temperature was maintained at $680^{\circ} \mathrm{C}$. The melt was then allowed to solidify in the mould. Figure 13 shows the stir casting unit for composite fabrication, and Figure 14 shows composite samples in the mould. Figure 15 shows the XRD spectra of the hybrid metal matrix $[\mathrm{Al} /(10 \% \mathrm{SiC}+10 \%$ fly ash $)]$ composites.

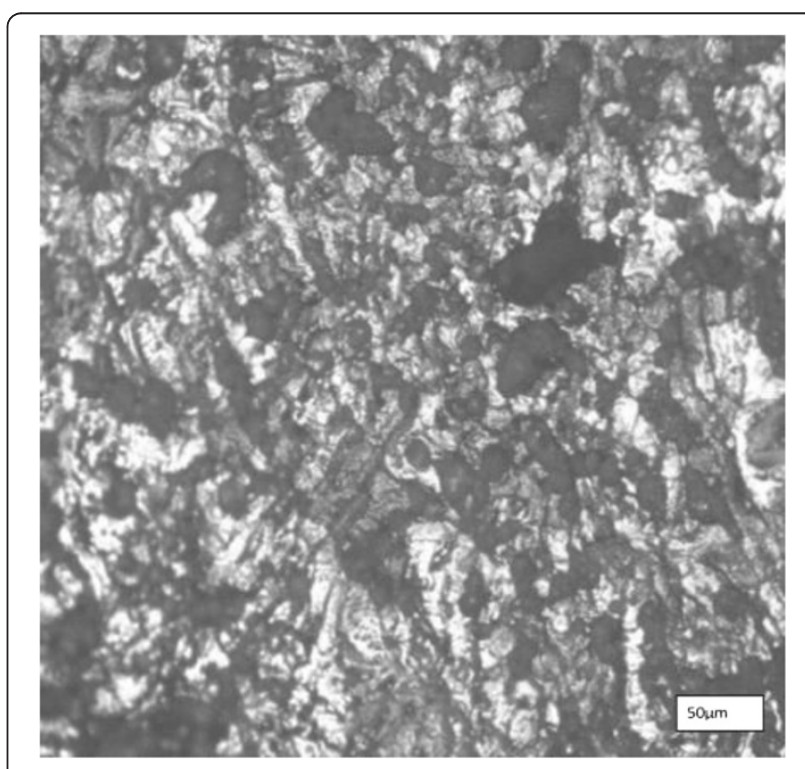

Figure 9 Photomicrograph showing Al-Mg-Si/2 wt.\% BLA-8 wt. $\% \mathrm{SiC}$ hybrid composite (Alaneme et al. 2013). 


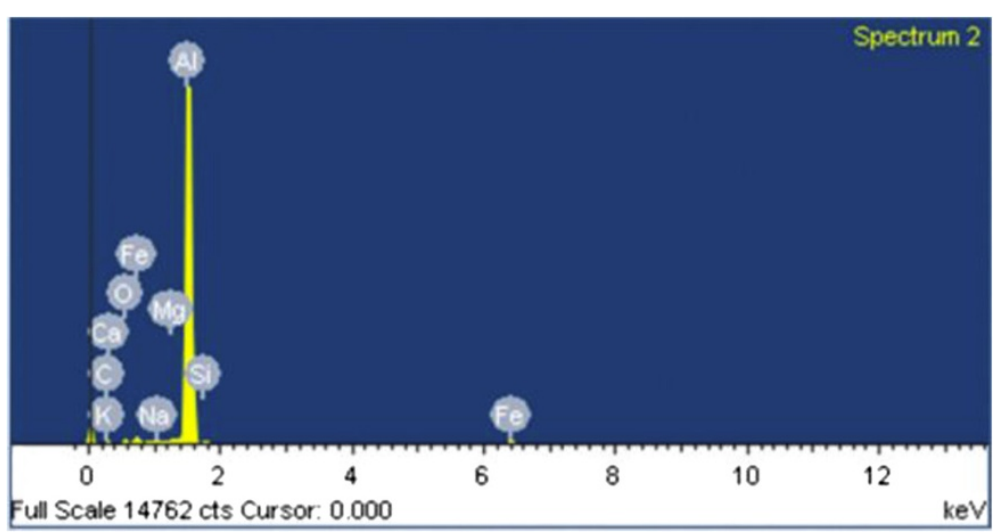

Figure 10 EDAX profile obtained from the Al-Mg-Si/2 wt.\% BLA-8 wt.\% SiC hybrid composite (Alaneme et al. 2013).

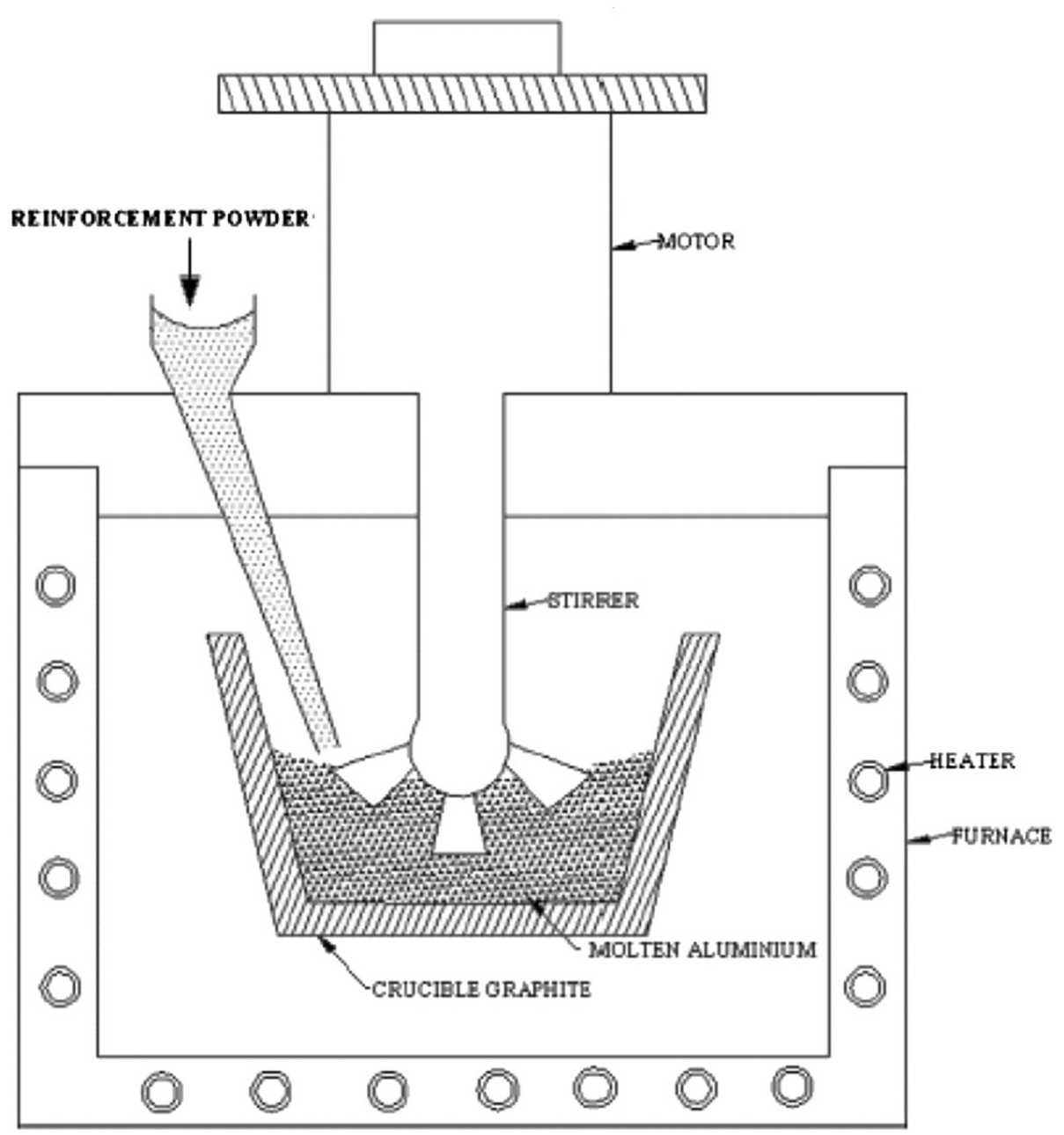

Figure 11 Layout of stir casting setup for composite fabrication (Umanath et al. 2013). 

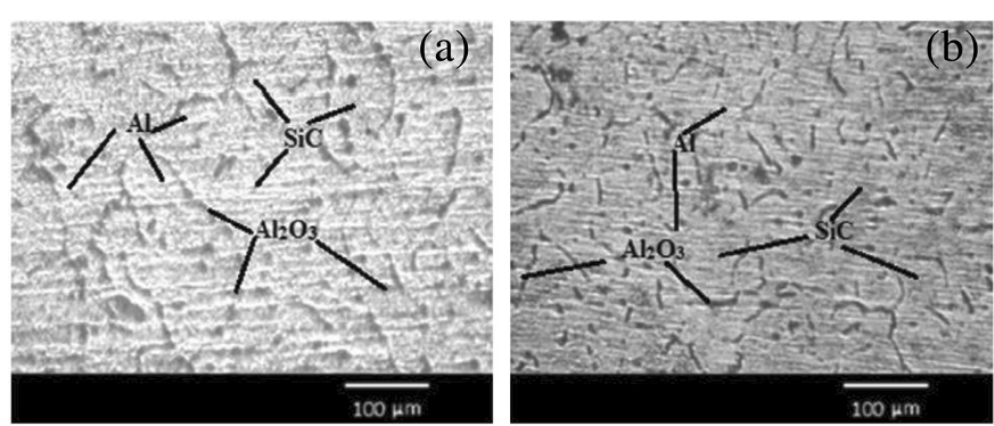

Figure 12 Optical micrographs of (a) Al6061 alloy $+5 \%$ vol. ( $\left.\mathrm{SiCp}+\mathrm{Al}_{2} \mathrm{O}_{3} \mathrm{p}\right)$ and (b) Al6061 alloy $+15 \%$ vol. ( $\left.\mathrm{SiCp}+\mathrm{Al}_{2} \mathrm{O}_{3} \mathrm{p}\right)(\mathrm{Umanath}$ et al. 2013).

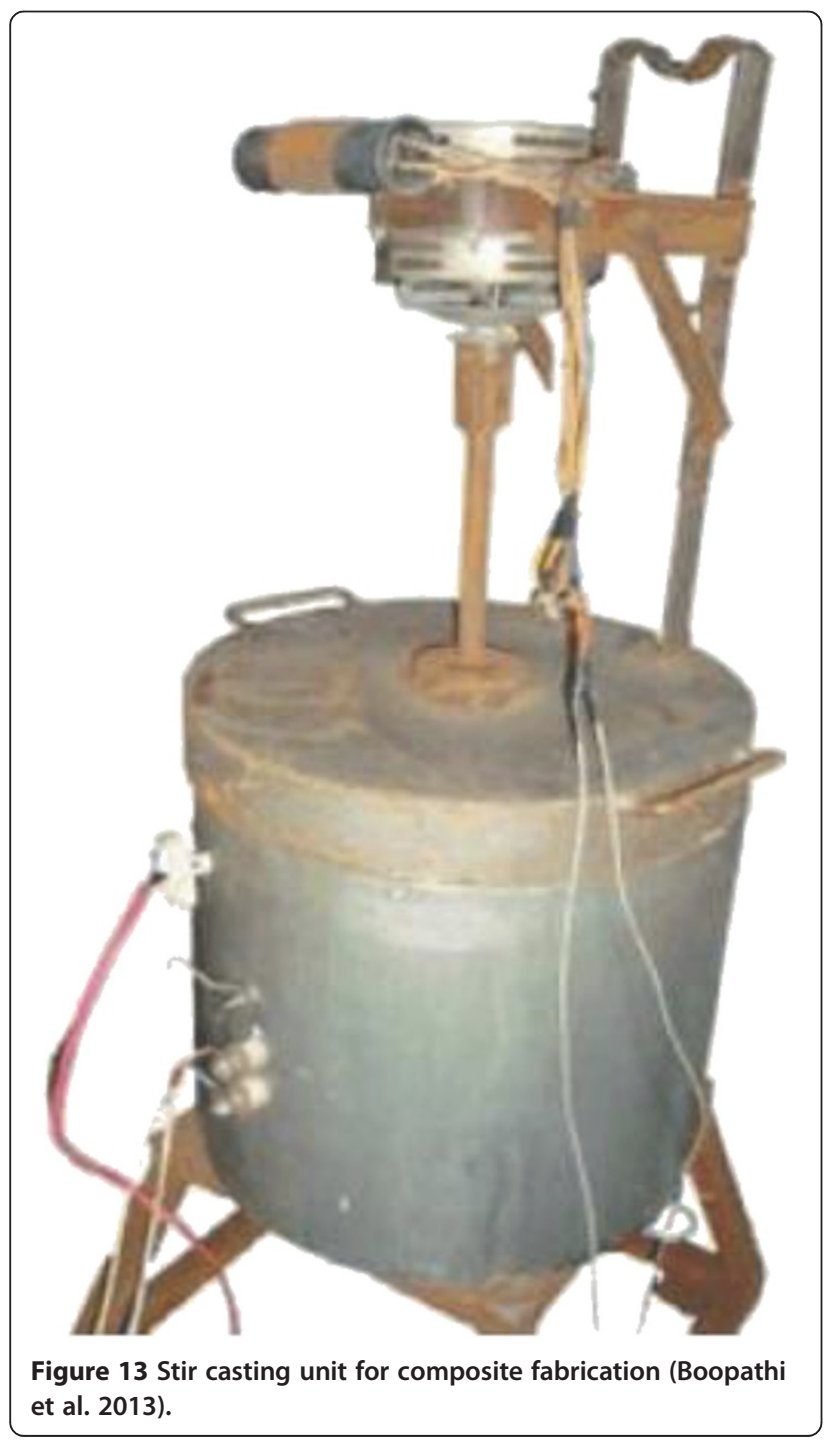

\section{Heat treatment of aluminium MMC}

Song et al. (1995) heat-treated 20 vol.\% of SiCp (of size 3 and $20 \mu \mathrm{m}$ ) reinforced $\mathrm{Al} 2014$ and $\mathrm{Al} 6061$ matrix composites to the T6 condition, which involved solution treatment at $530^{\circ} \mathrm{C}$ for $1 \mathrm{~h}$, quenching in cold water and then pre-ageing at room temperature for $20 \mathrm{~h}$. The materials were then aged at 50,100,150, 200 and $250^{\circ} \mathrm{C}$ for $1 \mathrm{~h}$ to study the effect of ageing temperature on the wear properties. Srivatsan and Prakash (1995) heat-treated the extruded SiC/Al 2080 composite billets to peak-aged T6 matrix condition, which includes solution heat treatment at $499^{\circ} \mathrm{C}$ for $4 \mathrm{~h}$ followed by cold water quenching. Subsequently, the composites were artificially aged at $177^{\circ} \mathrm{C}$ for $24 \mathrm{~h}$. $\mathrm{Xu}$ et al. (1997) heat-treated hot isostatic pressed $\mathrm{SiC} / \mathrm{Al} 359$ composites to the T6 condition, which involved solution treatment for $16 \mathrm{~h}$ at $538^{\circ} \mathrm{C}$, water quenching at above $65^{\circ} \mathrm{C}$ and artificial ageing for $5 \mathrm{~h}$ at $160^{\circ} \mathrm{C}$. The optical micrographs were obtained for composite F3S.20S (20 volume fraction and of median size $12.8 \pm 1.0 \mu \mathrm{m}$ of SiCp-reinforced AA 359 matrix composite) in as-cast condition and in HIP condition as shown in Figure 16a,b. Large pores are observed in the microstructure of as-cast composite; however, the porosity levels reduced effectively up to below $0.5 \%$ after the

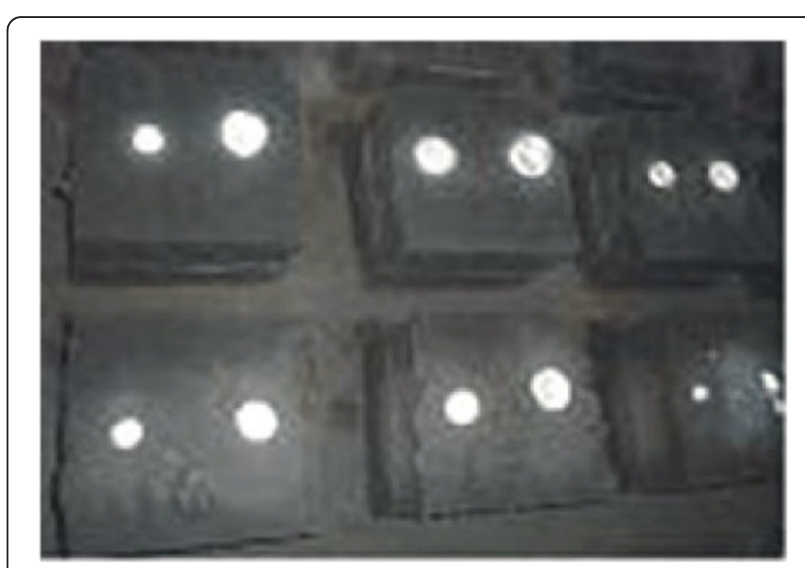

Figure 14 Composite samples in the mould (Boopathi et al. 2013). 


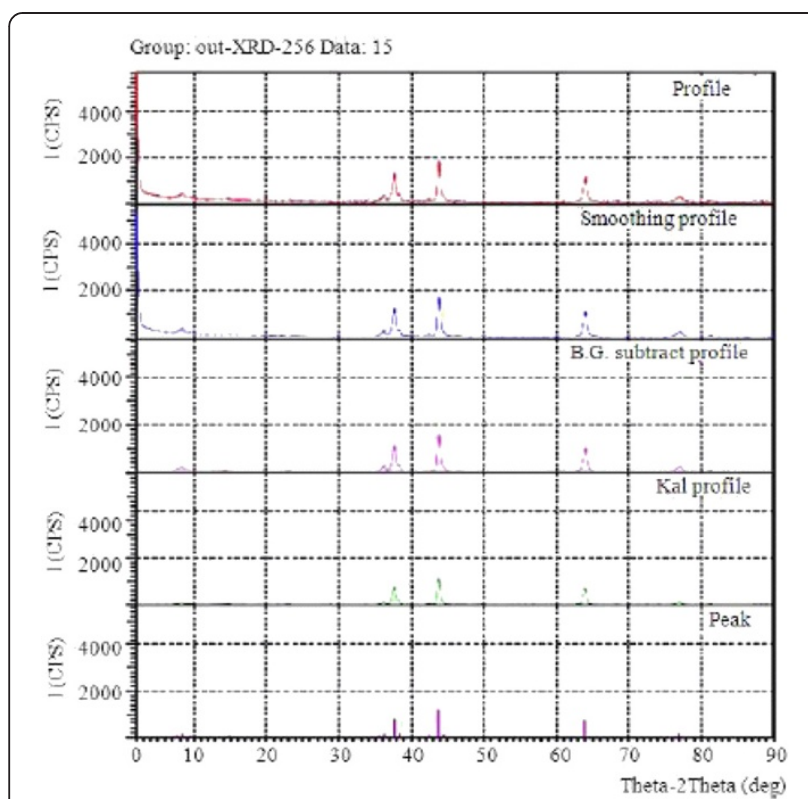

Figure $15 \mathrm{XRD}$ spectra of the hybrid metal matrix $[\mathrm{Al} /(10 \%$ $\mathrm{SiC}+10 \%$ fly ash)] composites (Boopathi et al. 2013).

HIP treatment of the composite. The reduction of porosity level was claimed for the diffusion bonding of adjacent pore surfaces as the composites were under high isostatic pressure and temperature during the HIP treatment.

Kwok and Lim (1999) solution-treated $\mathrm{Al} / \mathrm{SiC}$ composites at $515^{\circ} \mathrm{C}$ for $4 \mathrm{~h}$ in a muffle furnace and then quenched them to room temperature, and finally, ageing was carried out at a temperature of $175^{\circ} \mathrm{C}$ for $17 \mathrm{~h}$. Chen et al. (2000) heat-treated $\mathrm{Al} 356 / \mathrm{SiCp}$ composites to $\mathrm{T} 6$ condition at a temperature of $535^{\circ} \mathrm{C} \pm 5^{\circ} \mathrm{C}$ for $6 \mathrm{~h}$ and then quenched them in water at $80^{\circ} \mathrm{C}$. Finally, they were aged at a temperature of $200^{\circ} \mathrm{C}$ for $5 \mathrm{~h}$ in air. Davidson and Regener (2000) solution-treated SiCp/AA 6061 composites at $530^{\circ} \mathrm{C}$ for $1 \mathrm{~h}$ and then quenched them in cold water, followed by ageing for $8 \mathrm{~h}$ at $175^{\circ} \mathrm{C}$. Hamed et al. (2001) subjected SiCp-reinforced Al 359 composite to $\mathrm{T} 6$ heat treatment which involved solution treatment for $16 \mathrm{~h}$ at $530^{\circ} \mathrm{C}$, quenching at $60^{\circ} \mathrm{C}$ and then ageing for $9 \mathrm{~h}$ at $160^{\circ} \mathrm{C}$. Figure 17 shows the microstructures of the heat-treated $359 / \mathrm{SiC} / 10 \mathrm{p}$ composite materials.

A more uniform distribution of $\mathrm{SiC}$ particulates are observed in the microstructural image shown in Figure 17 as compared to that in Figure 16a, which clearly depicts the positive effect of heat treatment on uniformity in the distribution of reinforced ceramic particles in metal matrix composites.

Davim (2003) heat-treated, solutionized and aged A 356/ $20 \mathrm{vol} . \% \mathrm{SiCp}$ (of average dimension about $20 \mu \mathrm{m}$ ) composites at $\mathrm{T} 6$ condition for $5 \mathrm{~h}$ at $154^{\circ} \mathrm{C}$ to conduct turning experiments. Kalkanli and Yilmaz (2008) heat-treated SiC/Al 7075 composites according to ASM T6 heat treatment conditions, followed by solutionization at $480^{\circ} \mathrm{C}$ for 55 to $65 \mathrm{~min}$. Then, they were quenched and precipitation heat treated at $120^{\circ} \mathrm{C}$ for $24 \mathrm{~h}$. Balogun et al. (2008) heat-treated $\mathrm{Al} 6063 / \mathrm{SiC}$ metal matrix composite at $415^{\circ} \mathrm{C}$ for 1 -h soak time. Khalifa and Mahmoud (2009) solution heat-treated the as-cast and extruded $\mathrm{SiC} / \mathrm{Al} 6063$ composite samples at $530 \pm 3^{\circ} \mathrm{C}$ for $3 \mathrm{~h}$ and then quenched them in cold water. After cooling, specimens were artificially aged at $175 \pm 1^{\circ} \mathrm{C}$ to determine the peak hardness level attainable during age hardening and the time required for achieving such a hardness level. Rao et al. (2010) heat-treated SiC/Al 7009 composites in three stages, i.e. solution treatment for $8 \mathrm{~h}$ at $490^{\circ} \mathrm{C}$, then quenching in water and finally artificial ageing at a temperature of $180^{\circ} \mathrm{C}$ for $4,6,8$ and $10 \mathrm{~h}$ in order to get the better properties. Alaneme (2011) utilized four different temperature conditions to $\mathrm{SiCp} / \mathrm{Al} 6063$ composites, i.e. as-cast condition, and three others developed by heat treatment, namely solutionized and water quenched, artificially age hardened at $180^{\circ} \mathrm{C}$ and artificially age hardened at $195^{\circ} \mathrm{C}$. The solutionized and quenched temperature was achieved by solutionizing the samples at $550^{\circ} \mathrm{C}$ for $3 \mathrm{~h}$ and

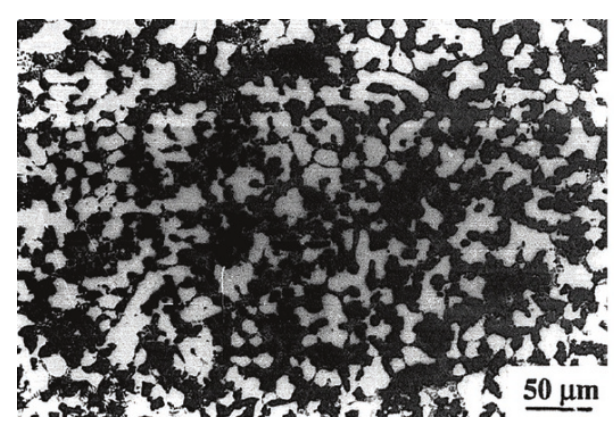

(a)

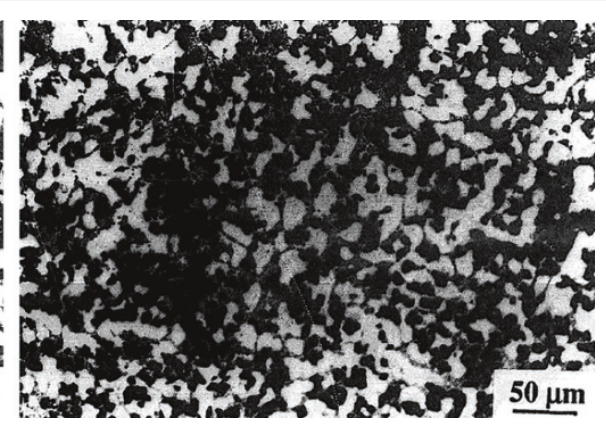

(b)

Figure 16 Optical micrographs of composite F3S.20S (i.e. AA 359/20 vol.\% SiCp) in the (a) as-cast condition and (b) hot isostatic pressed condition (Xu et al. 1997). 


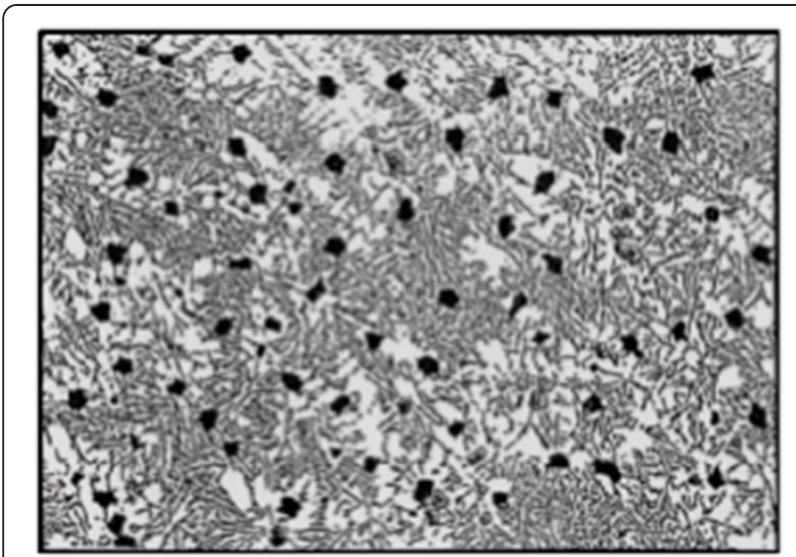

Figure 17 Microstructures of heat-treated 359/SiC/10p composite materials (Hamed et al. 2001).

then quenching in water. The two artificial ageing temperatures were achieved by initially solutionizing at $550^{\circ} \mathrm{C}$ for $3 \mathrm{~h}$ followed by water quenching. Age hardening treatments were performed at $180^{\circ} \mathrm{C}$ and $195^{\circ} \mathrm{C}$ for $2 \mathrm{~h}$ before water quenching. Alaneme and Aluko (2012) conducted solution treatment of $\mathrm{SiC} / \mathrm{Al} 6063$ composite samples in the furnace at $560^{\circ} \mathrm{C}$ for $2 \mathrm{~h}$, followed by water quenching. Ageing was then performed at $180^{\circ} \mathrm{C}$ for $3 \mathrm{~h}$, followed by water quenching. The optical micrographs obtained for as-cast $\mathrm{Al}$ 6063/9 vol.\% SiCp (of particle size $30 \mu \mathrm{m}$ ) composite and heat-treated (solution treatment followed by age hardening) $\mathrm{Al} 6063 / 9$ vol\% SiCp (of particle size $30 \mu \mathrm{m}$ ) composite are depicted in Figure 18a,b, respectively. Some localized clustering of $\mathrm{SiC}$ particles was observed in as-cast composite, whereas a more homogeneous distribution of the $\mathrm{SiC}$ particles was achieved in heat-treated composite. Another interesting conclusion from this comparison was that the volume percentage of silicon carbide reinforcement did not influence the pattern of distribution of $\mathrm{SiC}$ under as-cast and solution-treated followed by age-hardened conditions of composites.
Kumar and Dhiman (2013) performed T6 heat treatment of $\mathrm{SiC} / \mathrm{Gr} / \mathrm{Al} 7075$ hybrid metal matrix composite specimens, in which the solution treatment was done at $490^{\circ} \mathrm{C}$ for $2 \mathrm{~h}$, followed by water quenching, and ageing treatment was done at $120^{\circ} \mathrm{C}$ for $20 \mathrm{~h}$.

\section{Discussion}

After extensive literature study, it was observed that researchers adopt either powder metallurgy or molten metal stir casting technique, mostly the later one, for fabrication of ceramic-reinforced aluminium matrix composites, which may be due to the economical viability of this method. The technique has been summarized through eight steps.

Step 1. Selection of matrix metal and reinforcing agent

Any type of aluminium alloy may be chosen as matrix metal depending upon the application of the composite. Silicon carbide particulates have widely been used as reinforcing element; however, the use of aluminium oxide, boron carbide, graphite, fly ash and bamboo leaf ash also find their application as reinforcing agent during fabrication of aluminium matrix composites.

The size of SiC particulate chosen for reinforcement differs within a wide range, even from very fine size of $1 \mu \mathrm{m}$ to coarse size of $4,200 \mu \mathrm{m}$. For instance, very fine $\mathrm{SiC}$ particulate sizes of $1,2,3,3.5$ and $5 \mu \mathrm{m}$ were used by Adeosun et al. (2009), Yingfei et al. (2010), Schubert and Nestler (2011), Song et al. (1995), Lu et al. (1999) and Jayaram and Biswas (1999), respectively, whereas researchers like Kalkanli and Yilmaz (2008) and Jayaram and Biswas (1999) tried with coarse $\mathrm{SiC}$ particulate sizes of $240,300,420,840$ and $4,200 \mu \mathrm{m}$ for manufacturing $\mathrm{Al}$ matrix composites. However, particulate size of $\mathrm{SiC}$ used by majority of the researchers ranges in between 30 and $60 \mu \mathrm{m}$.

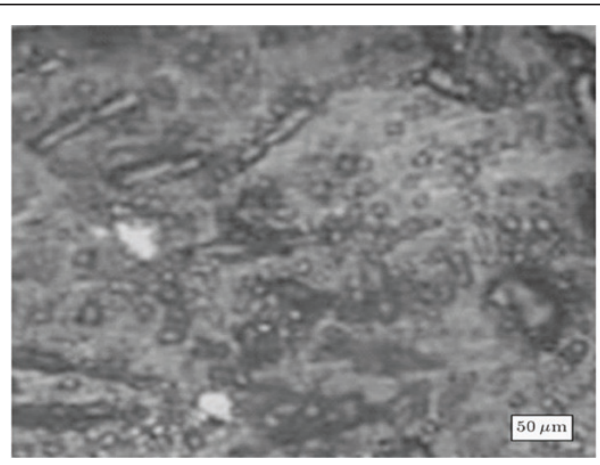

(a)

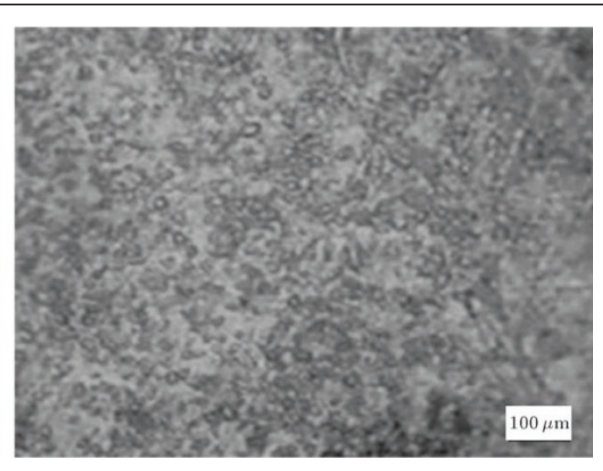

(b)

Figure 18 Optical micrographs of (a) as-cast Al 6063/9 vol.\% SiCp (of particle size $30 \mu \mathrm{m}$ ) composite (b) aged Al 6063/9 vol.\% SiCp (of particle size $30 \mu \mathrm{m}$ ) composite (Alaneme and Aluko 2012). 
Step 2. Determination of weight/volume fraction of reinforcement

The amount of $\mathrm{SiC}$ particles added to the matrix alloy is calculated either in the form of weight fraction or volume fraction of the composite. Low weight fractions of $\mathrm{SiC}$ (like 2.5\%, 5\% and 7.5\%) have been used by Suresha and Sridhara (2010), Singla et al. (2009) and Kumar et al. (2012), whereas high weight fractions (like 20\%, $22 \%, 25 \%$ and $30 \%$ ) have also been used for fabrication of AMCs by Hung et al. (1995) and Singla et al. (2009). Majority of the researchers use moderate value weight fractions (10\% to $15 \%)$ of $\mathrm{SiC}$ to fabricate AMCs. Similarly, volume fractions of $\mathrm{SiC}$ used vary from very low values like $0.2 \%, 0.5 \%, 3 \%, 5 \%$ and $6 \%$ (Srivatsan and Prakash 1995; Alaneme and Aluko 2012; Kalkanli and Yilmaz 2008; Alaneme 2011) up to high values like 20\%, 25\% and 30\% (Kalkanli and Yilmaz 2008; Schubert and Nestler 2011) through intermediate values like 10\%, 12\% and $15 \%$.

Step 3. Preheating and/or melting of matrix alloy

During fabrication of $\mathrm{Al}$ matrix composite, some researchers preheated the properly cleaned matrix alloy by distilled water (Kumar et al. 2012) or acetone (Babu and Krishnan 2012) up to a temperature of $450^{\circ} \mathrm{C}$ for 3 to $4 \mathrm{~h}$ (Singla et al. 2009), $300^{\circ} \mathrm{C}$ for 1 to $2 \mathrm{~h}$ (Khalifa and Mahmoud 2009), $500^{\circ} \mathrm{C}$ (Kumar et al. 2012) or $450^{\circ} \mathrm{C}$ for 3 to $4 \mathrm{~h}$ (Vanarotti et al. 2012) to make its surface oxidized. The preheating of matrix alloy was not conducted by a number of researchers; however, they have directly gone for melting the alloy above its liquidus temperature. During melting of matrix alloy, the temperature may be maintained in the range of $700^{\circ} \mathrm{C}$ to $950^{\circ} \mathrm{C}$. Most of the investigators have melted the $\mathrm{Al}$ alloy in the temperature range of $700^{\circ} \mathrm{C}$ to $800^{\circ} \mathrm{C}$ (Hamed et al. 2001; Kalkanli and Yilmaz 2008; Singla et al. 2009; Khalifa and Mahmoud 2009; Kumar and Dhiman 2013; Alaneme et al. 2013 and many more); however, some investigators have also gone beyond $800^{\circ} \mathrm{C}$ (Manoharan and Gupta 1999; Hassan et al. 2009; Ravesh and Garg 2012). Cocen and Onel (2002) and Kok (2008) melted $\mathrm{Al}$ alloy under argon gas protective atmosphere; however, Kumar and Dhiman (2013) used nitrogen gas during melting of $\mathrm{Al}$ alloy.

Step 4. Addition of all cover flux during melting and degasser after melting

During melting, the charge is to be fluxed with all cover flux or coverall to prevent dressing. The molten alloy is to be degasified by some suitable degasser, like tetrachlorethane or hexachloroethane or pure nitrogen gas, to minimize oxidation of molten metal (Khalifa and
Mahmoud 2009; Babu and Krishnan 2012; Kumar et al. 2012; Reddy and Zitoun 2010a).

\section{Step 5. Preheating of reinforcement}

The $\mathrm{SiC}$ particulates are to be preheated up to a certain temperature for 1 to $3 \mathrm{~h}$ before adding them into the molten Al alloy. Singla et al. (2009), Bains and Manna (2010) and Vanarotti et al. (2012) claim that preheating of reinforcing particles is necessary to get their surface oxidized; however, Manoharan and Gupta (1999), Ravesh and Garg (2012) Alaneme et al. (2013) and Boopathi et al. (2013) claim that preheating is necessary to remove moisture from reinforcing particulates and to improve wettability in matrix material. The temperature of preheating was ranged in between $300^{\circ} \mathrm{C}$ and $1,100^{\circ} \mathrm{C}$ (Khalifa and Mahmoud 2009; Bains and Manna 2010; Joardar et al. 2011; Behera et al. 2012 and many more).

Step 6. Manual/motorized stirring, addition of preheated reinforcing agent and wetting agent and temperature control of the abrasive slurry

As per some researchers (Natarajan et al. 2006; Kumar et al. 2012; Behera et al. 2012; Umanath et al. 2013), motorized stirring may be performed to molten aluminium and preheated $\mathrm{SiC}$ along with some suitable wetting agent may be added to the vortex created on the surface of molten aluminium due to continuous stirring, whereas some other researchers (Singla et al. 2009; Khalifa and Mahmoud 2009; Alaneme 2011; Alaneme and Aluko 2012; Vanarotti et al. 2012; Alaneme et al. 2013) are in favour of addition of preheated $\mathrm{SiC}$ along with wetting agent to the aluminium at semi-solid state, which can be achieved by cooling down the temperature of molten metal just below its melting point. After addition of preheated $\mathrm{SiC}$ particles and wetting agent to semi-solid aluminium, sufficient manual stirring is to be performed for 10 to 20 min to avoid difficulty of motorized mixing in the semi-solid state of the alloy. Thorough mixing of the slurry is required to achieve uniform distribution of SiCp in the $\mathrm{Al}$ matrix. Naher et al. (2004) reported that stirring the MMC slurry in semi-solid state, during the solidification process, helps to incorporate ceramic particles into the alloy matrix without any addition of wetting agent. After sufficient manual mixing, the composite slurry is reheated to fully liquid state and then automatic mechanical mixing is to be carried out for 10 to $20 \mathrm{~min}$. The mechanical stirring speed used are $220 \mathrm{rpm}$ (Bains and Manna 2010), 300 rpm (Alaneme 2011, Alaneme and Aluko 2012; Vanarotti et al. 2012), $400 \mathrm{rpm}$ (Alaneme et al. 2013), $600 \mathrm{rpm}$ (Singla et al. 2009) and even ultrasonic (Hamed et al. 2001). Preheated SiC may be added at very slow rate, for example, $0.5 \mathrm{~g} / \mathrm{min}$ (Hamed et al. 2001), $5 \mathrm{~g} / \mathrm{min}$ (Kalkanli and Yilmaz 2008) or 10 to $20 \mathrm{~g} / \mathrm{min}$ 
(Ravesh and Garg 2012). To prevent iron contamination in the abrasive slurry, the stirrer system may be coated with Zirtex 25 (Manoharan and Gupta 1999) or alumina (Kumar et al. 2012; Umanath et al. 2013).

After addition of preheated $\mathrm{SiC}$ to the molten $\mathrm{Al}$ alloy or to semi-solid Al alloy, as the case may be, some suitable wetting agent of required weight percentage is to be added and to be mixed thoroughly. Addition of wetting agent is required to achieve a strong bonding between the matrix alloy and the reinforcement particles by decreasing the surface energy (wetting angle) between them. Pure magnesium powder or borax may be used as wetting agent for the purpose. Addition of pure magnesium also enhances the fluidity of the molten metal. Behera et al. (2012) added 3 wt.\% of magnesium and Ozben et al. (2008) added 2 wt.\% of magnesium; however, Kumar and Dhiman (2013) added 1 wt.\% of magnesium as wetting agent and stated that addition of magnesium has two benefits, i.e. it acts as an alloying element and it reduces the surface tension thus improving wetting dispersion. Babu and Krishnan (2012) added magnesium in order to compensate for its losses during melting and for wetting purposes. Alaneme and Aluko (2012) used borax as wetting agent and added $\mathrm{SiC}$ and borax (dehydrated by heating at $250^{\circ} \mathrm{C}$ for $20 \mathrm{~min}$ ) mixture in the ratio 2:1, during fabrication of AMCs.

Step 8. Pouring the abrasive slurry to preheated mould

After sufficient mechanical mixing for about 10 to 20 min, the abrasive slurry is transferred to preheated mould, which may be made of sand, ceramic, cast iron or steel. The mould may be preheated up to a temperature within the range of $250^{\circ} \mathrm{C}$ to $760^{\circ} \mathrm{C}$ (Umanath et al. 2013; Kumar and Dhiman 2013; Vanarotti et al. 2012; Kalkanli and Yilmaz 2008; Singla et al. 2009), whereas the pouring temperature of molten abrasive slurry is maintained in the range of $680^{\circ} \mathrm{C}$ to $750^{\circ} \mathrm{C}$ (Boopathi et al. 2013; Hung et al. 1995; Kalkanli and Yilmaz 2008; Alaneme and Aluko 2012; Vanarotti et al. 2012; Joardar et al. 2011). After pouring molten abrasive slurry into the mould cavity, it is allowed to cool to atmospheric condition at different cooling rates.

Most of the researchers follow T6 condition of heat treatment for $\mathrm{SiC}$-reinforced $\mathrm{Al}$ matrix composite, which involves solution treatment at a certain temperature for a certain period of time, quenching in water followed by ageing at a certain temperature for a certain duration. The solution treatment temperature and time and the ageing temperature and time depend upon the type of the $\mathrm{Al}$ alloy used for composite fabrication.

\section{Conclusions}

An attempt has been done to outline various methods of fabrications of aluminium matrix composite, giving special emphasis to stir casting method. Various steps involved in this method has been discussed briefly, and emphasis has been given to different key points, such as selection of weight or volume fraction of $\mathrm{SiC}$ in the composite, $\mathrm{SiC}$ particulate size, preheating temperature of $\mathrm{SiC}$, preheating and melting temperature of $\mathrm{Al}$ matrix, stirring speed during agitation of the composite slurry, use of flux, degasser and wetting agent, preheating temperature of the mould and pouring temperature of composite slurry into the mould. T6 condition of heat treatment for composites of various $\mathrm{Al}$ alloy has been outlined briefly.

\section{Competing interests}

The authors declare that they have no competing interests.

\section{Authors' contributions}

DKD performed thoroughly the literature on fabrication of MMCs and carried out fabrication of MMCs by stir casting method. PCM studied characterization of MMCs by various techniques including Mechanical tests, physical tests and optical tests. SS participated in the sequence alignment and drafted the manuscript. SP participated in the sequence alignment and drafted the manuscript. All authors read and approved the final manuscript.

Received: 22 February 2014 Accepted: 13 May 2014

Published online: 07 August 2014

\section{Reference}

Adalarasan, R, Shanmuga, PC, Arunachalam, R, \& Sudhir, R. (2011). An evaluation of mechanical properties and microstructure of dispersion strengthened Al-6063 obtained by in-situ fabrication. International Journal on Design and Manufacturing Technologies, Sathyabama University, India, 5(2), 01-05.

Adeosun, SO, Balogun, SA, Sanni, OS, \& Ayoola, WA. (2009). Improving the strength and ductility of wrought aluminum through particle addition. Pittsburgh: Materials Science and Technology (MS\&T).

Alaneme, K. (2011). Corrosion behaviour of heat-treated Al-6063/ SiCp composites immersed in $5 \mathrm{wt} \% \mathrm{NaCl}$ solution. Leonardo Journal of Sciences, 18, 55-64.

Alaneme, KK, \& Aluko, AO. (2012). Fracture toughness (K 1 C and tensile properties of as-cast and age-hardened aluminium (6063)-silicon carbide particulate composites. Scientia Iranica A, 19(4), 992-996.

Alaneme, KK, Ademilua, BO, \& Bodunrin, MO. (2013). Mechanical properties and corrosion behaviour of aluminium hybrid composites reinforced with silicon carbide and bamboo leaf ash. Tribology in Industry, 35(1), 25-35.

Babu, TSM, \& Krishnan, NM. (2012). An experimental investigation of turning $\mathrm{Al} / \mathrm{SiC} / \mathrm{B}_{4} \mathrm{C}$ hybrid metal matrix composites using ANOVA analysis. Scholarly Journal of Engineering Research, 1(2), 25-31.

Bains, HS, \& Manna, A. (2010). A study on turning of Al (6063) /5 vol.\% SiC and Al(6063)/10 vol.\% SiC-MMC. Talwandi Sabo, Distt.Bathinda: National Conference on Advancements and Futuristic Trends in Mechanical and Materials Engineering, at Yadavindra College Engineering.

Balogun, SA, Esezobor, DE, Adeosun, SO, Oladoye, AM, Osoba, LO, \& Kuforiji, C. (2008). Development of particulate reinforced aluminium metal matrix composite. Benin City: 2nd International Conference on Engineering Research \& Development Innovations.

Behera, R, Mohanta, NR, \& Sutradhar, G. (2012). Distribution of SiC particulates in stir cast aluminium alloy metal matrix composites and its effect on mechanical properties. International Journal of Emerging Trends in Engineering and Development, 1, 194-200.

Boopathi, M,M, Arulshri, KP, \& lyandurai, N. (2013). Evaluation of mechanical properties of aluminium alloy 2024 reinforced with silicon carbide and fly ash hybrid metal matrix composite. American Journal of Applied Sciences, 10(3), 219-229.

Borrego, A, Fernandez, R, Cristina, MC, Ibanez, J, \& González-Doncel, GG. (2002). Influence of extrusion temperature on the microstructure and the texture of 6061Al-15 vol.\% SiCW PM composites. Composites Science and Technology, $62,731-742$ 
Chen, R, Iwabuchi, A, \& Shimizu, T. (2000). The effect of a T6 heat treatment on the fretting wear of a $\mathrm{SiC}$ particle-reinforced $\mathrm{A} 356$ aluminum alloy matrix composite. Wear, 238, 110-119.

Cocen, U, \& Onel, K. (2002). Ductility and strength of extruded SiCp/aluminiumalloy composites. Composites Science and Technology, 62, 275-282.

Davidson, AM, \& Regener, D. (2000). A comparison of aluminium-based metalmatrix composites reinforced with coated and uncoated particulate silicon carbide. Composites Science and Technology, 60, 865-869.

Davim, JP. (2003). Design of optimization of cutting parameters for turning metal matrix composites based on orthogonal arrays. Journal of Material Processing Technology, 132, 340-344

Divecha, AP, Fishman, SG, \& Karmarkar, SD. (1981). Silicon carbide reinforced aluminum - a formable composite. Journal of Metals, 33(9), 12-17.

Fang, Q, Sidky, P, \& Hocking, MG. (1997). Erosive wear behaviour of aluminium based composites. Materials \& Design, 18(4/6), 389-393.

Fu-min, X, Chi-man, WUL, Guang-wei, H, \& Yi, T. (2007). Compression creep behavior of high volume fraction of $\mathrm{SiC}$ particles reinforced Al composite fabricated by pressureless infiltration. Chinese Journal of Aeronautics, 20, 115-119.

Hamed, OA, Shady, MA, \& El-Desouky, AR. (2001). Creep behavior of a cast 359SiC10p aluminum composite. Materials and Design, 22, 473-479.

Hassan, AM, Alrashdan, A, Hayajneh, MT, \& Mayyas, AT. (2009). Wear behavior of Al-Mg-Cu-based composites containing SiC particles. Tribology International, 42, 1230-1238.

Hung, NP, Boey, FYC, Khor, KA, Oh, CA, \& Lee, HF. (1995). Machinability of cast and powder-formed aluminium alloys reinforced with $\mathrm{SiC}$ particles. Journal of Materials Processing Technology, 48, 291-297.

Hung, NP, Loh, NL, \& Xu, ZM. (1996). Cumulative tool wear in machining metal matrix composites. Part II: machinability. Journal of Materials Processing Technology, 58, 114-120.

Jayaram, V, \& Biswas, SK. (1999). Wear of $\mathrm{Al}_{2} \mathrm{O}_{3}-\mathrm{SiC}-(\mathrm{Al}, \mathrm{Si})$ melt oxidised ceramic composites. Wear, 225-229, 1322-1326.

Joardar, H, Das, NS, \& Sutradhar, G. (2011). An experimental study of effect of process parameters in turning of LM6/SiCP metal matrix composite and its prediction using response surface methodology. International Journal of Engineering, Science and Technology, African Journals Online (AJOL), 3(8), 132-141.

Kalkanli, A, \& Yilmaz, S. (2008). Synthesis and characterization of aluminum alloy 7075 reinforced with silicon carbide particulates. Materials and Design, 29, 775-780.

Khalifa, TA, \& Mahmoud, TS. (2009). Elevated temperature mechanical properties of Al Alloy AA6063/SiCp MMCs. London: Proceedings of the World Congress on Engineering.

Ko, BC, \& Yoo, YC. (1998). Hot deformation behaviour of AA2124 composites reinforced with both particles and whiskers of SiC. Composites Science and Technology, 58, 479-485.

Kok, M. (2008). A study on the machinability of $\mathrm{Al}_{2} \mathrm{O}_{3}$ particle reinforced aluminium alloy composite. Madrid: 11th Int. Inorganic Bonded Fibre Composites Conference.

Kumar, R, \& Dhiman, S. (2013). A study of sliding wear behaviors of Al-7075 alloy and Al-7075 hybrid composite by response surface methodology analysis. Materials and Design, 50, 351-359. doi:10.1016/j.matdes.2013.02.038.

Kumar, NVR, \& Dwarakadasa, ES. (2000). Effect of matrix strength on the mechanical properties of $\mathrm{Al}-\mathrm{Zn}-\mathrm{Mg} / \mathrm{SiCP}$ composites. Composites Part A: Applied Science and Manufacturing, 31(10), 1139-1145.

Kumar, DR, Narayanasamy, R, \& Loganathan, C. (2012a). Effect of glass and SiC in aluminum matrix on workability and strain hardening behavior of powder metallurgy hybrid composites. Materials and Design, 34, 120-136.

Kumar, SMS, Rao, KP, \& Girish, DP. (2012b). Corrosion rate and tensile strength of aluminium/SiC metal matrix composites in seawater. International Journal of Advanced Engineering Research and Studies (IJAERS), 1(3), 313-315.

Kwok, JKM, \& Lim, SC. (1999). High-speed tribological properties of some Al/SiCp composites: I. Frictional and wear-rate characteristics. Composites Science and Technology, 59, 55-63.

Lu, YX, Meng, XM, Lee, CS, Li, RKY, Huang, CG, \& Lai, JKL. (1999). Microstructure and mechanical behaviour of a SiC particles reinforced Al-5Cu composite under dynamic loading. Journal of Materials Processing Technology, 94, 175-178.

Manoharan, M, \& Gupta, M. (1999). Effect of silicon carbide volume fraction on the work hardening behaviour of thermomechanically processed aluminiumbased metal-matrix composites. Composites: Part B, 30, 107-112.

Mindivan, H, Kayali, ES, \& Cimenoglu, H. (2008). Tribological behavior of squeeze cast aluminum matrix composites. Wear, 265, 645-654.
Naher, S, Brabazon, D, \& Looney, L. (2004). Development and assessment of a new quick quench stir caster design for the production of metal matrix composites. Journal of Materials Processing Technology, 166, 430-439.

Natarajan, N, Vijayarangan, S, \& Rajendran, S. (2006). Wear behaviour of A356/ 25SiCp aluminium matrix composites sliding against automobile friction material. Wear, 261, 812-822.

Ozben, T, Kilickap, E, \& Cakır, O. (2008). Investigation of mechanical and machinability properties of $\mathrm{SiC}$ particle reinforced Al-MMC. Journal of Materials Processing Technology, 198(1-3), 220-225.

Pandey, PC. (2004). Composite materials, web-based course. Bangalore, India: NPTEL, IISC.

Rao, RN, Das, S, Mondal, DP, \& Dixit, G. (2009). Dry sliding wear behaviour of cast high strength aluminium alloy (Al-Zn-Mg) and hard particle composites. Wear, 267, 1688-1695.

Rao, RN, Das, S, Mondal, DP, \& Dixit, G. (2010). Effect of heat treatment on the sliding wear behaviour of aluminium alloy ( $\mathrm{Al}-\mathrm{Zn}-\mathrm{Mg}$ ) hard particle composite. Tribology International, 43, 330-339.

Ravesh, SK, \& Garg, TK. (2012). Preparation \& analysis for some mechanical property of aluminium based metal matrix composite reinforced with SiC \& fly ash. International Journal of Engineering Research and Applications (IJERA), 2(6), 727-731

Reddy, CA, \& Zitoun, E. (2010a). Matrix Al-alloys for silicon carbide particle reinforced metal matrix composites. Indian Journal of Science and Technology, 3(12), 1184-1187.

Reddy, CA, \& Zitoun, E. (2010b). Tensile behavior of Al 6063/ $/ \mathrm{Al}_{2} \mathrm{O}_{3}$ particulate metal matrix composites. International Journal of Applied Engineering Research, 1(3), 542-552.

Ronald, BA, Vijayaraghavan, L, \& Krishnamurthy, R. (2007). Studies on grooving of dispersion strengthened metal matrix composites. Materials Forum, 31, 102-109.

Sahin, Y, \& Murphy, S. (1996). Wear performance of aluminium alloy composites containing unidirectionally-oriented silicon carbide coated boron fibres. Wear, 197, 248-254.

Schubert, A, \& Nestler, A. (2011). Enhancement of surface integrity in turning of particle reinforced aluminium matrix composites by tool design. 1st CIRP conference on surface integrity (CSI). Procedia Engineering, 19, 300-305.

Singla, M, Dwivedi, DD, Singh, L, \& Chawla, V. (2009). Development of aluminium based silicon carbide particulate metal matrix composite. Journal of Minerals \& Materials Characterization \& Engineering, 8(6), 455-467.

Song, WQ, Krauklis, P, Mouritz, AP, \& Bandyopadhyay, S. (1995). The effect of thermal ageing on the abrasive wear behaviour of age hardening $2014 \mathrm{Al} /$ Sic and 6061 Al/SIC composites. Wear, 185, 125-130.

Srivatsan, TS, \& Prakash, A. (1995). The quasi-static fracture behaviour of an aluminum alloy metal-matrix composite. Composites Science and Technology, 53, 307-315.

Surappa, MK. (2003). Aluminium matrix composites: challenges and opportunities. Sadhana, 28(Parts 1 \& 2), 319-334

Suresha, S, \& Sridhara, BK. (2010). Wear characteristics of hybrid aluminium matrix composites reinforced with graphite and silicon carbide particulates. Composites Science and Technology, 70, 1652-1659.

Umanath, K, Kumar, KP, \& Selvamani, ST. (2013). Analysis of dry sliding wear behaviour of Al6061/SiC/Al2O3 hybrid metal matrix composites. Composites: Part B, 53, 159-168.

Vanarotti, M, Kori, SA, Sridhar, BR, \& Padasalgi, SB. (2012). Synthesis and characterization of aluminium alloy A356 and silicon carbide metal matrix composite. Singapore: International Proceedings of Computer Science and Information Technology.

Weinert, K. (1993). A consideration of tool wears mechanism when machining metal matrix composites (MMC). CIRP Ann, 42, 95-98.

Xu, ZM, Loh, NL, \& Zhou, W. (1997). Hot isostatic pressing of cast SiCp-reinforced aluminium-based composites. Journal of Materials Processing Technology, 67, 131-136.

Yingfei, G, Jiuhua, X, \& Hui, Y. (2010). Diamond tools wear and their applicability when ultra-precision turning of SiCp/2009Al matrix composite. Wear, 269, 699-708.

Zhiqiang, S, Di, Z, \& Guobin, L. (2005). Evaluation of dry sliding wear behavior of silicon particles reinforced aluminum matrix composites. Materials and Design, 26, 454-458.

\section{doi:10.1186/s40712-014-0006-7}

Cite this article as: Das et al:: Fabrication and heat treatment of ceramic-reinforced aluminium matrix composites - a review.

International Journal of Mechanical and Materials Engineering 2014 1:6. 